PNL-7694

UC-372

S

\title{
Catalysis-By-Design Impacts Assessment
}

L. L. Fassbender

R. K. Sen

J. K. Young

May 1991

Prepared for the U.S. Department of Energy under Contract DE-AC06-76RLO 1830

Pacific Northwest Laboratory

Operated for the U.S. Department of Energy

by Battelle Memorial Institute 


\title{
DISCLAIMER
}

This report was prepared as an account of work sponsored by an agency of the United States Government. Neither the United States Government nor any agency thereof, nor Battelle Mernorial Institute, nor any of their employees, makes any warranty, expressed or implied, or assumes any legal liability or responsibility for the accuracy, completeness, or usefulness of any information, apparatus, product, or process disclosed, or represents that its use would not infringe privately owned rights. Reference herein to any specific commercial product, process, or service by trade name, tradernark, manufacturer, or otherwise does not necessarily constitute or imply its endorsement, recommendation, or favoring by the United States Government or any agency thereof, or Battelle Memorial Institute. The views and opinions of authors expressed herein do not necessarily state or reilect those of the United States Government or any agency thereof.

\author{
PACIFIC NORTHWEST LABORATORY \\ operated by \\ BATTELLE MEMORIAL INSTITUTE \\ for the \\ UNITED STATES DEPARTMENT OF ENERGY \\ under Contract DE.AC06-76RLO 1830
}

Printed in the United States of America

Available to DOE and DOE contractors from the Office of Scientific and Technical Information, P.O. Box 62, Oak Ridge, TN 37831; prices available from (615) \$76-8401. FTS 626-8401.

Available to the public from the National Technical Information Service, U.S. Department of Commerce, 5285 Port Royal Rd., Springfield, VA 22161. 
PNL -7694

UC -372

\title{
CATALYSIS-BY-DESIGN IMPACTS ASSESSMENT
}

\author{
L. L. Fassbender \\ R. K. Sen $(a)$ \\ J. K. Young
}

May 1991

Prepared for

the U.S. Department of Energy

under Contract DE-ACO6-76RLO 1830

Pacific Northwest Laboratory

Richland, Washington 99352

(a) R. K. Sen \& Associates, Washington, D.C. 
.

. 


\section{EXECUTIVE SUMMARY}

Catalysis is the acceleration of a chemical reaction by the addition of a substance (the catalyst) which itself undergoes no permanent chemical change in the process. Traditionally, identifying new catalysts has been more of an art than a science. A phenomenal number of trials can be required to do an exhaustive search for a new catalyst, and it is often sheer luck that any useful catalyst is discovered at all. After a discovery is made, numerous time-consuming tests, calculations, and evaluations are required to transform the discovery into a commercial product.

Catalyst researchers have always recognized the need to develop a detailed understanding of the mechanisms of catalytic processes, and have hoped that it would lead to developing a theoretical predictive base to guide the search for new catalysts. This understanding allows one to develop a set of hierarchical models, from fundamental atomic-level ab-initio models to detailed engineering simulations of reactor systems, to direct the search for optimized, efficient catalyst systems.

During the last two decades, the explosions of advanced surface analysis techniques have helped considerably to develop the building blocks for understanding various catalytic reactions. Complementary to this development, the advances in computation technology have allowed scientists to undertake larger and larger theoretical simulations of molecular dynamics.

An effort to couple these theoretical and experimental advances to develop a set of hierarchical models to predict the nature of catalytic materials is a program entitled "Catalysis-by-Design (CBD)." This program was supported by the Energy Conversion and Utilization Technologies (ECUT) Division of the U.S. Department of Energy's (DOE) Office of Conservation and Renewable Energy. Although the ECUT Division no longer exists due to a major reorganization, this study still refers to ECUT because industry is familiar with the ECUT name and supports the ECUT philosophy.

The enabling methodologies developed in the CBD Program could significantiy improve the effectiveness of the catalyst R\&D process. The computational mode?s evolving from the CBD approach could be used to optimize the 
microstructure and performance of a newly discovered catalyst for a particular application. It may even be possible to use CBD to design catalysts a priori for specific applications. If successful, this approach can potentially lead to significant energy savings through the development of more efficient cataTytic processes, and also have a tremendous impact in maintaining the compet $;$ tiveness of U.S. chemical, biochemical, petroleum refining, and petrochemical industries.

In assessing the potential impacts of CBD on U.S. industry, the key point to remember is that the value of the program lies in developing a novel methodology to search for new catalyst systems. Industrial researchers can then use this methodology to develop proprietary catalysts. To ensure that the CBD methodology is relevant to industry, it is important to have a panel of industrial advisors assisting in its development. It must also be emphasized that CBD needs a long-term focus that must be funded to completion. As the CBD Program is getting under way, some chemical and/or biochemical reactions will be selected for developing and testing the methodology. Industry believes that these should be long-shot possibilities, which they are not supporting at this time because of the risks involved, but will have profound impacts if successful catalysts are eventually developed.

Most companies involved in catalyst R\&D have two types of ongoing projects. The first type, what we call "market-driven R\&D," are projects that support and improve upon a company's existing product lines. A major portion (as much as 60\%) of any company's catalyst R\&D is devoted to these types of projects. Projects of the second type, "technology-driven R\&D," are longer term, involve the development of totally new catalysts, and are initiated through scientists' research ideas. The CBD approach will impact both types of projects. However, this analysis indicates that the near-term impacts will be on "market-driven" projects.

The conclusions and recommendations presented in this report were obtained by the authors through personal interviews with individuals involved in a variety of industrial catalyst development programs and through the three CBD workshops held in the summer of 1989. 
CONTENTS

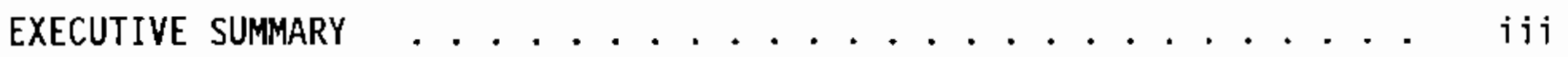

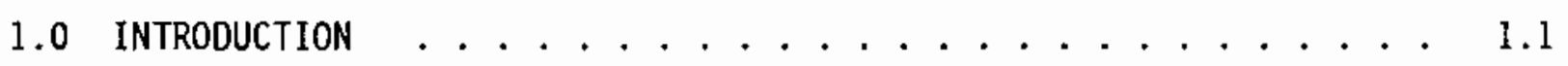

2.0 BACKGROUND $\ldots \ldots \ldots \ldots \ldots . \ldots \ldots \ldots$

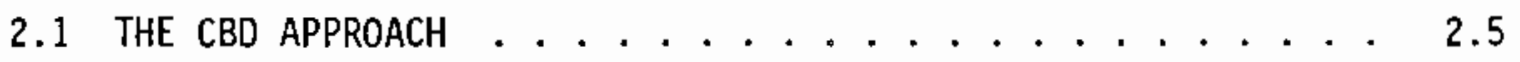

2.2 ASSESSMENT METHODOLOGY . . . . . . . . . . . . . 2.9

3.0 POTENTIAL IMPACTS OF IMPROVED CATALYSTS. . . . . . . . . . . . .

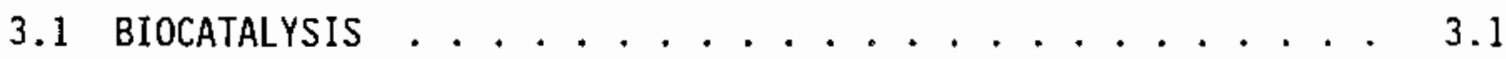

3.2 CHEMICAL CATALYSIS . . . . . . . . . . . 3.6

3.2 .1 Fluid Catalytic Cracking . . . . . . . . . 3.7

3.2 .2 Alkylation .......................... 3.10

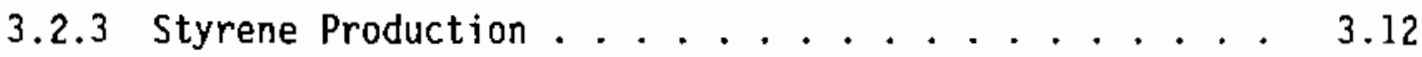

3.3 SUMMARY OF CASE STUDIES . . . . . . . . . . . 3.13

4.0 INDUSTRIAL CATALYST RESEARCH $\ldots \ldots \ldots . \ldots . \ldots . \ldots . \ldots$

4.1 MARKET-DRIVEN PROJECTS ......................... 4.1

4.2 TECHNOLOGY-DRIVEN PROJECTS .................. 4.4

4.3 CATALYST SCREENING . . . . . . . . . . . . . 4.7

5.0 RESULTS FROM INTERVIEWS AND WORKSHOPS ........... 5.1

5.1 INDUSTRIAL INTERVIEHS . . . . . . . . . . 5.1

5.1 .1 Company A . . . . . . . . . . . . 5.2

5.1 .2 Company B . . . . . . . . . . . . 5.5

5.1 .3 Company C . . . . . . . . . . . . . 5.8

5.1 .4 Company D . . . . . . . . . . . . . 5.9

5.1 .5 Company E . . . . . . . . . . . . . 5.12

5.1 .6 Company F .................. 5.13 
5.1 .7 Company $G \ldots \ldots \ldots . \ldots . \ldots . \ldots . \ldots$

5.1 .8 Company H .......................... 5.19

5.1 .9 Company I . . . . . . . . . . . 5.22

5.2 WORKSHOP PROCEEDINGS ..................... 5.23

5.2.1 Biocatalysis Workshop . . . . . . . . . 5.24

5.2.2 Chemical Catalysis Workshop . . . . . . . . . 5.30

6.0 MECHANISMS FOR GOVERNMENT/INDUSTRY COLLABORATION . . . . . . . . 6.1

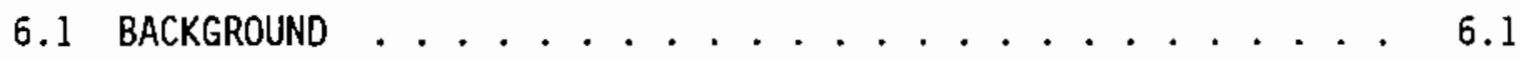

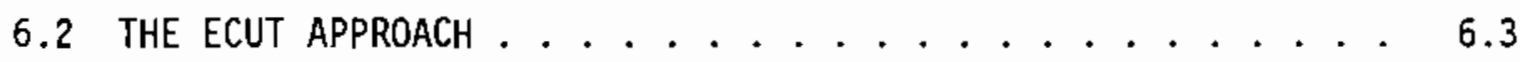

6.3 INDUSTRIAL PERSPECTIVE . . . . . . . . . . . 6.6

6.4 CONTRACTUAL MECHANISMS . . . . . . . . . . . . 6.8

6.5 PREFERENTIAL TREATMENT OF U.S. INDUSTRY . . . . . . . 6.10

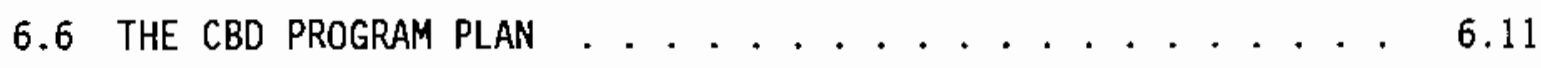

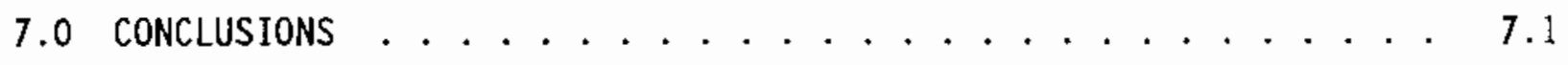

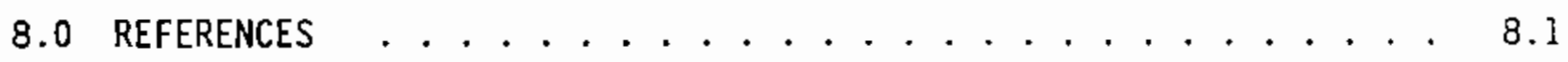




\section{FIGURES}

2.1 The Design of Primary Components of a Catalyst . . . . . . 2.2

2.2 Volcano Plot Showing the Correlation of Hydrodesulfurization Catalytic Activity with Heat of Formation for Mono- and Bimetallic Sulfides as Reported by Chianelli et al. (1984) . . . 2.3

3.1 Years by which Biotechnology will have Significant Impact on Particular U.S. Industries . . . . . . . . . . 3.5

3.2 Ideal Alkylation Process . . . . . . . . . . . 3.12

3.3 Ideal Styrene Process Schematic . . . . . . . . . . . 3.14

4.1 Flow Diagram for Market-Driven R\&D Projects . . . . . . . . 4.3

4.2 Flow Diagram for Technology-Driven R\&D Projects . . . . . . . 4.5 


\section{TABLES}

1.1 U.S. Consumption of Catalysts in 1984, Including Captive

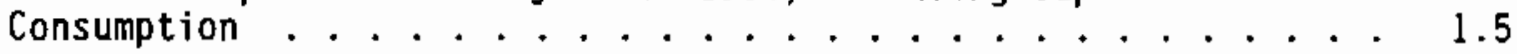

2.1 Frequently Used Techniques of Surface Science for Studies

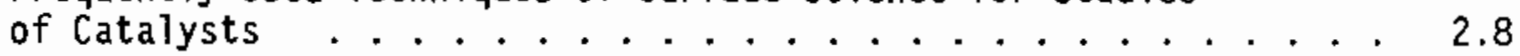

3.1 Potential Oxychemicals from Renewable Resources

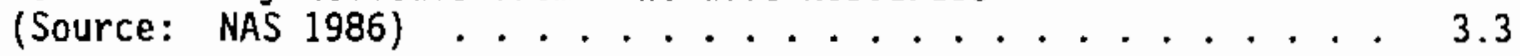

3.2 0xychemical Markets for Innovations in Biotechnology

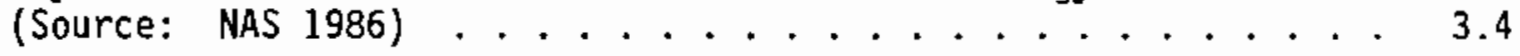

3.3 1983 Energy Requirements for Major Chemical Products

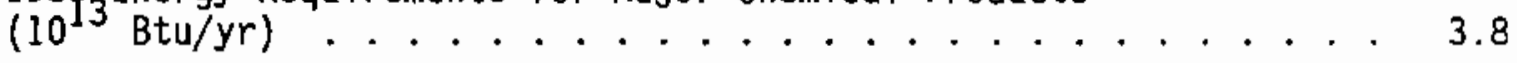

5.1 Questionnaire for Interviews ............ 5.3

6.1 ECUT Combustion Technology Program . . . . . . . . . . 6.4 


\subsection{INTRODUCTION}

Catalysis is the phenomenon where a chemical reaction is accelerated by the addition of a substance (the catalyst) which itself does not undergo any permanent change in the process. The term "catalysis" was coined by Berzeljus, but it was 0stwald who first demonstrated that a catalyst can increase the rate of a chemical reaction (Sinfelt 1987). Inherent in this concept was the fact that chemical reactions occurring in the presence of a catalyst must also be capable of occurring in its absence, although at a much lower rate; a typical example would be the reaction of hydrogen and oxygen to produce water. Thermodynamically, it is a very favorable reaction. Nonetheless, a mixture of these two gases in a molecular ratio of 2:1 can be stored for years at room temperature without any detectable evidence of their reacting. Yet, a catalyst such as finely divided platinum promotes an almost instantaneous reaction.

Catalytic processes have been useful to mankind since ancient times. The production of wine and vinegar by fermentation is an example. While the nature of the catalytic process involving enzymes was certainly not known then, the process was in widespread use. In modern times, our industrial socjety has come to rely on catalysis for a variety of products ranging from energy and feedstocks to specialty chemicals and pharmaceuticals.

The energy sector is heavily dependent on catalysts. For example, the petroleum refining industry uses a variety of catalysts to process petroleum into finished products such as gasoline and petrochemical feedstocks. The demands for improved catalysts will increase as domestic refiners adjust to the depletion of the world's light crude oil reserves and begin to process more heavy crude oils. Although $52 \%$ of the current free world production is light crude 0 ils, heavy crude represents $72 \%$ of the proven reserves (Hettinger et a1. 1984). The heavy crudes have a higher molecular weight distribution, which means that yields of light products such as gasoline are lower. New catalysts to crack the heavy crudes with high space-time yields are needed.

The situation is similar with clean coal and synthetic fuel technologies. Catalysts are essential in the clean burning of coal and in all coal-and 
biomass-derived synthetic fuel processes. The Mobil methanol-to-gasoline (MTG) process is one example. Although the clean coat processes are currently receiving a great deal of attention, there is very little focus on synthetic fuels. The collapse of many synfuel projects with falling petroleum prices during the last decade contributed to this situation. However, there is still a need for synthetic fuels in the long term, and efficient catalysts for synfuel processes will undoubtedly be in great demand.

The domestic commodity chemicals industry is under intense competitive pressures. Higher feedstock prices, the high cost of capital, and occasional7y restricted access to markets have decreased the profitability of domestic producers, while increasing the market shares of foreign producers. The United States has historically had a significant balance-of-trade surplus in commodity chemicals. However, the competitive pressures have led to a gradual decline in the surplus. In adapting to the changing environment, U.S. chemical companies have been shifting from commodity chemicals to high-valueadded specialty chemicals. This trend has kept the domestic producers competitive.

In the long term, a diminished U.S. role in commodity chemicals will be deleterious to our industrial economy, since these chemicals are essential to maintaining our standard of living. Productivity improvements are the only mechanisms through which U.S. chemical companies will remain competitive in this important business segment, and catalysts are vital to achieving this objective. Optimized catalysts will allow industry to improve its competitive posture by obtaining high yields while maintaining feedstock flexibility.

The commercial potential for biotechnology processes is enormous. The Office of Technology Assessment (OTA 1984) estimated that the market potential for genetically engineered chemicals could be as high as $\$ 6.6$ billion, and as much as $\$ 12.6$ billion for methane produced via bioprocesses. In spite of these projections, industry considers the use of biotechnology to produce commodity chemicals as too risky. Factors contributing to the high risk are the poor understanding of biocatalytic processes and the inadequate performance and short lifetimes of biocatalysts. 
There is a strong need to improve our technology base in biocatalysis, which becomes apparent when we compare the tremendous resources being committed by our major competitors (Europe and Japan) in this important area. An additional benefit of biotechnology is its ability to produce important chemicals with very few undesirable by-products. Biocatalytic processes, thus, could make major contributions in mitigating many of our current environmental problems. For example, such processes could potentially convert carbon dioxide, one of the major greenhouse gases, into useful chemical feedstocks and other products.

The increased national focus on environmental problems will require major changes in our industrial infrastructure and our lifestyles. At the present time, many of our urban centers are incapable of meeting current federal air quality regulations. Concerns about acid rain and global climate change are gaining in importance, and issues relating to the handling and management of hazardous wastes are increasingly leading to demands for environmentally acceptable technology. The Administration and Congress have worked together to reauthorize the Clean Air Act to include tougher emissions regulations. The Resource Conservation and Recovery Act (RCRA) regulations to control hazardous waste disposal are being continuously strengthened. Major industrial sectors such as utilities, transportation, and chemicals will be profoundly impacted. These trends make it clear that control of undesirable emissions from both stationary and transportation sources will be mandated.

Increasing use of catalytic processes will be necessary to meet the strict emissions requirements. The chemical and petrochemical industries will require new catalysts with improved yields and specificity to reduce, if not el iminate, environmentally undesirable by-products. Automobile exhaust catalysts are here today, and new improved catalysts will undoubtedly be needed as more stringent environmental regulations are enacted. This trend is clearly global, as evidenced by the belated but strong effort by the European Economic Community (EEC) to implement catalytic convertors for automobiles. Estimates are that growth in pollution control catalysts for both stationary and transportation applications will approach $20 \%$ annually over the next five years (Chemical Week, June 28, 1989). 
The potential impact of catalysts in the energy industry is exemplified by the gasoline-selective zeolite catalysts. The first commercial application of zeolites as cracking catalysts occurred in 1959. Their improved performance and stability compared to the conventional silica-alumina systems led to rapid deployment as commercial cracking catalysts. By 1976, zeolites alone contributed $\$ 3$ billion in savings for the petroleum industry in reduced petroleum refining costs (Chen and Degnan 1988).

The importance of catalysts in the chemical and petrochemical industries is also evidenced by the fact that about $90 \%$ of the products in these industries are derived from catalytic processes (Hegedus 1987). In 1984, the worldwide usage of catalysts approached $\$ 2.7$ billion, with $53 \%$ of the catalysts being used in the United States. Table l.1 lists U.S. catalytic markets in more detail. The three largest uses are automobile emissions control, catalytic cracking, and a variety of polymerization processes.

In $1984, \$ 1.33$ billion worth of catalysts sold to U.S. chemical and petrochemical companies produced a total of $\$ 259$ billion worth of products. That is, $\$ 195$ worth of products were produced for every dollar spent on catalysts (Hegedus 1987), which clearly illustrates the tremendous economic leverage of the catalytic industries. However, despite their enormous impacts, the annual sales of catalysts in the United States are small, accounting for only $3.5 \%$ of the $\$ 54$ billion U.S. specialty chemicals market (Siwolop 1989). The prime reason for the small catalyst market is the sheer power and reusability of good catalysts; a chemical processor only needs a small amount of catalyst to produce a huge volume of products. For example, an annual production of only 500,000 kilograms of zeolite catalyst is adequate to service the complete worldwide demand for fluid catalytic cracking of petroleum to produce gasoline (Chen and Degnan 1988).

An unfortunate consequence of this fact is that catalyst research in this country has become stagnant. Forecasts of slow sales growth (approximately $3 \%$ over the next 5 years) coupled with severe cutbacks of government support for the synfuels effort has led to both government and industry putting cataiyst research on the back burner. In contrast, major European and Japanese chemical companies have been expanding their roles through joint ventures, 
TABLE 1.1. U.S. Consumption of Catalysts in 1984, Including Captive Consumption (Source: Hegedus 1987. Reprinted by permission of John Wiley \& Sons, Inc.)

\begin{tabular}{|c|c|}
\hline & (s million) \\
\hline $\begin{array}{l}\text { Chemical Processing(d) } \\
\text { Polymerization } \\
\text { Organic syntheses } \\
\text { Oxidation, ammoxidation, and oxychlorination } \\
\text { Hydrogen, ammonia, and methanol syntheses } \\
\text { Hydrogenation } \\
\text { Dehydrogenation } \\
\text { Total }\end{array}$ & $\begin{array}{r}235 \\
85 \\
80 \\
50 \\
30 \\
10 \\
490\end{array}$ \\
\hline $\begin{array}{l}\text { Petroleum Refining (a)(b) } \\
\text { Catalytic.cracking } \\
\text { Hydrotreating } \\
\text { Hydrocracking } \\
\text { Catalytic reforming } \\
\text { Total }\end{array}$ & $\begin{array}{r}255 \\
75 \\
40 \\
20 \\
390\end{array}$ \\
\hline $\begin{array}{l}\text { Emission Confrgl(a) } \\
\text { Automptjuve } \\
\text { Other }(\mathrm{d}) \\
\text { Total }\end{array}$ & $\begin{array}{r}445 \\
5 \\
450\end{array}$ \\
\hline Total Catalyst Consumption & 1330 \\
\hline $\begin{array}{l}\text { (a) Strategic Analysis, Inc. (1985). } \\
\text { (b) Excluding } \$ 155 \text { million for } \mathrm{HF} \text { and } \mathrm{H}_{2} \mathrm{SO}_{4} \text { a } \\
\text { (c) Including an estimated } \$ 160 \text { million for } \mathrm{n} \\
\text { (d) Estimated. }\end{array}$ & $\begin{array}{l}\text { l]kylation catalysts } \\
\text { loble metals. }\end{array}$ \\
\hline
\end{tabular}

Consumption

Chemical Processing (a)

Organic syntheses

235

80

50

10

hydrogenation

Petroleum Refining(a)(b)

Catalytic.cracking

255

Catalytic.crack

Hydrocracking

40

$\frac{20}{390}$

Automotive $(c)$ (d)

ther (d)

$\frac{5}{450}$

1330

acquisitions, and enhanced R\&D efforts. European chemical giants such as AKZO, Degussa, and Siemens have expanded their activities both domestically and in the U.S. market. With both automobile and stationary emissions control requirements increasing, Europe is a growth market for the catalyst business. The Japanese catalyst industry, although small, is attempting to leapfrog the competition by acquiring technology through joint ventures.

The decline of U.S. catalysis R\&D is of concern, especially as one recognizes that catalyst research is primarily a time-consuming trial-and-error effort. For example, it is not unusual to wait a decade or longer for new catalyst systems to be in commercial use after their initial discovery 
(Meisel 1988), as was the case with the zeolite catalyst for fluid catalytic cracking. The current lower level of R\&D activity will most likely slow down new catalyst introduction a decade from now. To prevent such an occurrence, it is desirable to develop tools that will enhance the efficacy of catalyst research and shorten the time between discovery and product commerciatization.

At the beginning of this impacts assessment study, the Energy Conversion and Utilization Technologies (ECUT) Division of the U.S. Department of Energy (DOE) was developing a program which they called "Catalysis-By-Design" (CBD). This program is a collaborative effort between industry and ECUT to develop enabling technologies that will help industry to tailor-make catalysts for specific applications. If successful, it will serve DOE's dual missions of ensuring the nation's energy security and assisting U.S. industry in maintaining and improving its competitive posture. Although DOE has recently completed a major reorganization of its Office of Conservation and Renewable Energy (where ECUT used to reside) and the ECUT Division no longer exists, this study still refers to ECUT because the industrial constituency is familiar with the ECUT name and is supportive of the ECUT philosophy.

The ability to predict catalytic properties and to design catalysts for specific applications has been a goal of catalyst researchers. Many theories and rules-of-thumb have been developed and are used to map out strategies for screening new catalysts. Progress, nonetheless, has been 1 imited, which underscores the complex nature of catalysis. It requires a multidisciplinary effort involving advanced techniques to characterize catalyst surfaces and study the reaction dynamics, including most importantly the nature of the transition states, to develop a good understanding of catalytic processes. When this experimental knowledge is combined with advanced theoretical and computational capabilities to model catalytic processes, there is the potential to develop practical computational software that can be used by industrial researchers as design tools for catalyst R\&D.

There have been revolutionary advances in all these areas in the last two decades. For example, surface characterization techniques such as scanning tunneling microscopy (STM) allow us to look at catalyst surfaces on the atomic level. Reaction dynamics can now be studied in the femto-second time 
frame, which allows scientists to look directly at transition states. As experimental insights regarding atomic- and molecular-level processes occurring during catalysis have increased, so has the fundamental theoretical framework to describe it mathematically. The rapid proliferation of supercomputers has resulted in the capability to model complex catalytic processes; it is the synergistic impact of these related advances that greatly increases the chances of success of the CBD Program. A distinguished panel of experts in theoretical and experimental catalysis research met with internationally recognized computer scientists at Texas A\&M University in September 1984, to evaluate the efficacy of the CBD approach. They concluded that the time is right from a technological perspective to undertake this effort (refer to page 2.4 for further discussion).

The question remains whether DOE should support the CBD Program. Therefore, this report examines that issue in terms of DOE's dual missions of energy security and international competitiveness. It also considers the appropriateness of the CBD Program to ECUT's mission of developing an industrially relevant technology base for energy-efficient technologies. The report describes the CBD Program, attempts to assess its potential impacts on U.S. industry, and recommends models for effective government/industry collaboration. 


\subsection{BACKGROUND}

Since Ostwald discovered that a catalyst alters the rate of a chemical reaction (Sinfelt 1987), there has been great interest in understanding the detailed mechanisms of catalytic reactions. Such an understanding is desired not only to satisfy the innate scientific curiosity, but it also contributes much to developing a predictive base that allows catalyst researchers to tailor-make catalysts for specific applications. Obviously, the latter objective has been of great interest to the catalyst industry. Over the years, academic and industrial researchers have pursued this goal aggressively. Progress has been steady, but at a rather slow pace. This is primarily because catalysis is an extremely complicated phenomenon. Figure 2.1 (Trimm 1980) conceptually illustrates the variety of inputs necessary to have a satisfactory basis for predicting catalytic activity. Thus, screening of potential materials based on some well-established empirical rules continues to be the norm for catalyst R\&D.

Major improvements in experimental techniques for the study of very fast reaction kinetics, the atomic-level characterization of catalytic sites, and our ability to tailor-make catalysts for specific reactions, have occurred in the last two decades. Theoretical tools to describe reaction dynamics and energetics have been refined, and the availability of supercomputers has helped in performing complex theoretical calculations. With these advances, there has been a gradual shift from the over-reliance on empirical screening to a more knowledge-based approach to catalyst R\&D.

A typical example of this approach is the detailed investigation of the catalytic hydrodesulfurization of dibenzothiophene (Chianelli 1985). When the catalytic activity for hydrodesulfurization is plotted as a function of the heat of formation of the metal-sulfide as shown in Figure 2.2, a clear volcano-shaped relationship appears. This is interpreted in terms of the we11-known "intermediate bonding" principle of catalysis, a concept stating that maximum hydrodesulfurization rates will be seen with catalysts exhibiting metal-sulfur bond strengths that are neither too weak nor too strong. In this case, the optimum appears to be at about $35 \mathrm{kcal} / \mathrm{g}$-atom of metal. 


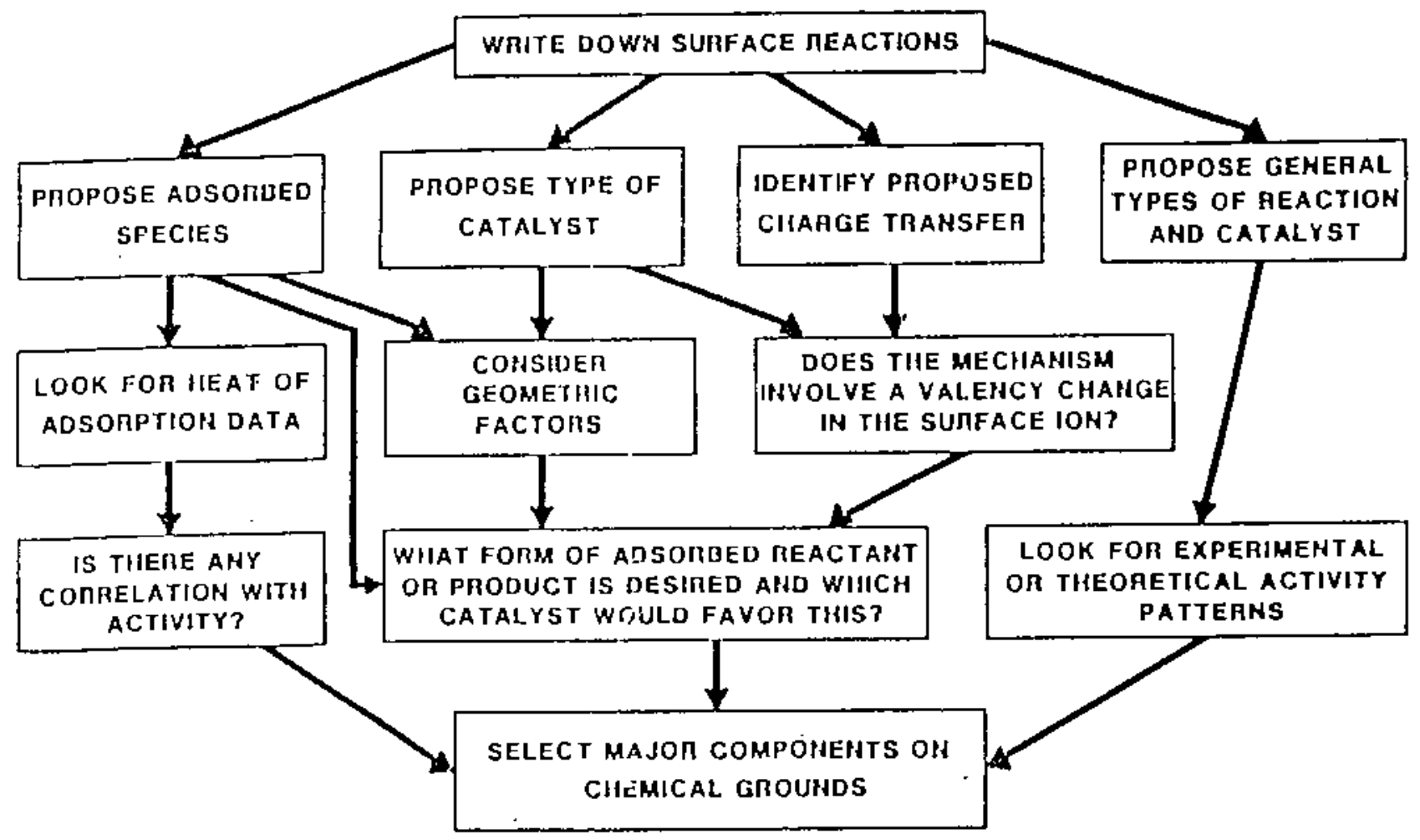

FIGURE 2.1. The Design of Primary Components of a Catalyst (as proposed by Trimm). Theory and modeling can augment each of the steps in this process. (Source: Trimm 1980)

Similar volcano plots have been obtained with many other catalytic reactions, and it is important to note that this principle has been experimentally established for individual catalytic reactions through systematic screening of a variety of materials. Also, despite the existence of a qualitative scientific explanation for this principle, there is still no sound quantitative theoretical basis that allows generalization of the concept into a predictive tool to search for new catalysts. Thus, for each catalytic reaction, a laborious experimental program is required to establish such volcano plots so that the optimum catalyst composition can be identified. This is just one of many examples of catalyst research issues where a similar situation exists. For example, important areas such as structure-activity correlations and metalsupport interactions fall into this category, indicating a clear need for a 


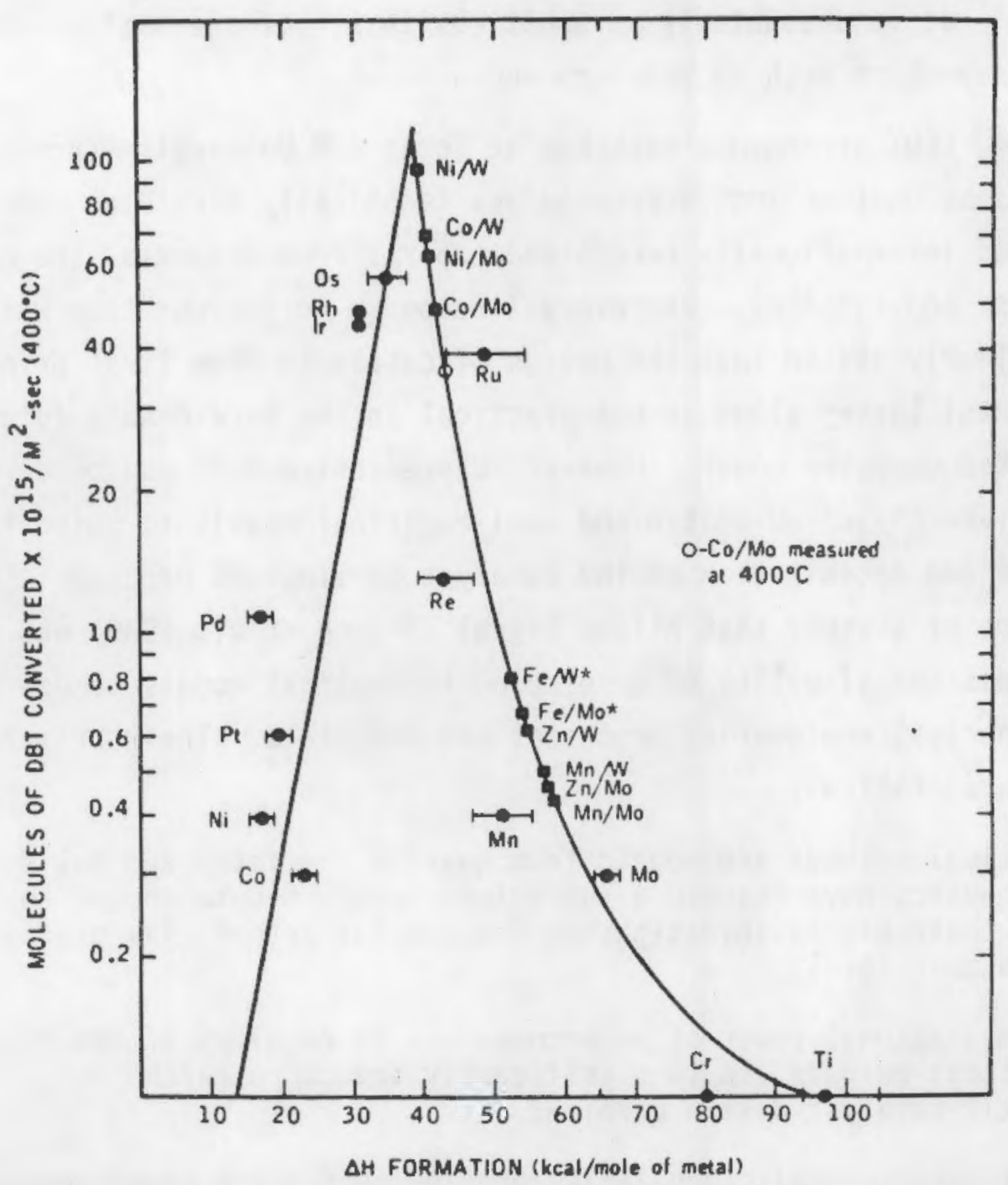

FIGURE 2.2. Volcano Plot Showing the Correlation of Hydrodesulfurization Catalytic Activity with Heat of Formation for Mono- and Bimetallic Sulfides (Source: Chianelli et al. 1985)

greater integration of advanced experimental, theoretica1, and computational techniques to develop a true predictive base for catalysis.

It would be misleading to claim that catalysts are developed entirely in an empirical way; in fact, the role of empiricism has been decreasing with time. Recently developed catalysts are better understood than their predecessors, and a greater degree of preselection was employed in their development. These advances led ECUT to pose the question "Is now a propitious time to start a directed, applied research program to design catalysts from first 
principles?" It is undoubtedly an ambitious task, but one that is desired by catalyst researchers both in industry and academia.

In 1984, ECUT arranged a workshop at Texas A\&M University (Broach et al. 1989) to assess whether such a program was technically feasible. The attendees included internationally recognized experts from academia, the national laboratories, and industry. The overall response to the question was yes. The group clearly stated that the design of catalysts from first principles and fundamental theory alone is not practical in the foreseeable future, even with unlimited computer power. However, a predictive base can be developed through a hierarchy of ab-initio and semi-empirical models to guide the characterization and optimization of the catalyst development process. The workshop was part of a study that Allied Signal (Broach et al. 1989) was conducting to assess the viability of developing theoretical models to design and optimize practical engineering processes and materials. Their primary conclusions are as follows:

1. Theoretical methods and models from quantum chemistry and solidstate physics have reached a sufficient level of development to enable their use in investigating fundamental interfacial processes at an atomic level.

2. The computational power of supercomputers is required if the theoretical methods are to significantly impact research in realistic catalyst design problems.

3. Current experimental capabilities provide sufficient knowledge about surface and interfacial regions to guide initial modeling and to verify theoretical predictions. However, many details of the surface and interface are not well understood, and improvements will be needed.

4. Development of the capability to design and optimize improved catalysts on the basis of the modeling of fundamental chemical and physical processes is realizable within the next 5 to 10 years.

Based on these recommendations, ECUT initiated the Catalysis-by-Design (CBD) Program to couple advanced experimental and theoretical methods to develop a set of hierarchical models that can be considered expert systems for assisting in the "designing" of new catalysts. The CBD Program's objective is to effectively integrate theoretical and experimental advances to develop 
detailed computer models for predicting catalytic behavior. These models can then be used by industrial researchers to design new catalysts.

\subsection{THE CBD APPROACH}

The realistic models emanating from this program will definitely require supercomputers. Access to supercomputers has been increasing rapidly, and in the near future, most researchers will have ready access to these sophisticated systems, (e.g., the National High-Speed Data Transmission Initiative and the Initiative in High-Speed Computing sponsored by the Bush Administration will certainly increase the availability of these computational tools). Thus, catalyst researchers will most likely have ready access to the supercomputer systems that will be required for use of codes developed in the CBD Program.

It is important, however, to restate that the CBD Program seeks a synergy of experimental, theoretical, and computational efforts to serve a specific need in catalyst research; it does not plan to displace experiment by theory. Catalyst design is only effective if it provides new and exciting leads for experimental evaluation of potentially new catalytic systems.

Catalysis is a complex phenomenon, and developing design tools requires a thorough understanding of many component processes. In its most basic form, a heterogeneous catalytic reaction consists of the following steps:

1. mass transfer from bulk to catalyst boundary layer

2. diffusion through boundary layer

3. adsorption (physical and chemical) and migration on catalyst surface

4. surface reactions and diffusion to produce new chemisorbed states (reaction intermediates)

5. creation of chemisorbed and/or physisorbed product states

6. diffusion and transport of the products.

There are two basic phenomena involved in understanding industrial catalysis. The first is the atomic/molecular-level detail on how a catalyst works to modify the transition state of a reaction and, thus, affects the 
yield and/or selectivity. The second phenomenon that needs to be understood is how the reactants are effectively transported to, and the products removed from, the reaction site on the catalyst. Both are vitally important for the design of effective catalysts.

Fluid dynamics control the transport of the reactants to the catalyst boundary layer and the removal of the products from the boundary layer. Voluminous literature exists on transporting fluids through porous media (supported catalysts), and this information is used in addressing reactor design and optimizing the porous structure of catalysts (Boston 1990). This area, therefore, will not be emphasized initially in the CBD Program because it appears that industry is investing adequate resources to deal with it.

Rather, the CBD Program will focus on the more difficult task of developing the knowledge base to model the intrinsic catalytic activity from a detailed knowledge of the electronic structure and energetics of the species involved in a catalytic reaction. This will obviously include the reactants, the products, and the catalyst itself. The objective is to predict the structure and energetics of the rate-determining step and the transition state so that the optimum properties required of the catalyst can be readily established.

If $C B D$ is to evolve into a design tool for industrial catalyst researchers, the program must focus on the study of real catalysts in actual operating conditions as opposed to the study of model systems using wel1defined conditions and single-crystal catalysts. It is certainly a more difficult approach, but it is clearly more desirable and will be the preferred approach for the CBD Program.

Following this philosophy, the CBD approach will address the following tasks to build on the experimental and theoretical databases currently available to develop self-consistent models for predicting the properties of catalytic systems: 
- Adsorption/Desorption of Reactants and Products - The first step in any heterogeneous catalysis is the adsorption of the reactants onto the catalyst. The final step is the desorption of the products. Understanding the atomic-level phenomena involved is essential to understanding how catalysts operate.

- Surface Migration/Diffusion - It is common for adsorbed species to diffuse on the catalyst surface and rearrange into a configuration suitable for the subsequent reaction. The linkages between these surface diffusion/migration effects and the catalytic activity are not clearly understood.

- Reaction Dynamics and Kinetics - Kinetic and thermodynamic measurements of catalytic reactions are well established. Transition state theories are commonly used to explain the kinetic data and derive mechanistic conclusions. Recent efforts have been to study the kinetics in very short time scales to follow the molecular dynamics of the reaction. Techniques such as femto-second spectroscopy allow us to study reactions in the time scales in which bonds are formed and broken. These experimental and theoretical techniques are now allowing researchers to understand the reaction mechanisms and the transition states in detail.

- Structure/Activity Relationships - The structural features of catalysts profoundly affect their properties. Different catalytic sites exhibit different energetics for adsorption and migration. The reaction rates are also vastly different. Practical catalysts contain a multitude of such sites, and understanding the contribution of these sites is essential if a practical model to predict catalytic behavior is to be developed.

The experimental and theoretical parts of the research will focus on developing frameworks to correlate molecular properties with relevant macroscopic parameters necessary to design catalyst systems; some experimental techniques required for such an effort are listed in Table 2.1. The theoretical effort will be a combination of semi-empirical and ab-initio calculations, depending on the level of experimental data and the complexity of the system. Initially, the emphasis will be on semi-empirical techniques to establish the boundary conditions and to predict experimentally observed correlations (e.g., adsorption energy as a function of the electronic properties and adsorption isotherms). Molecular dynamic calculations to predict the rate-determining step will also be attempted.

The ultimate goal of the CBD Program is a state-of-the-art computer code for the use of industrial researchers. Converting theoretical methodologies 
IABLE 2.1. Frequently Used Techniques of Surface Science for Studies of Catalysts (Source: Pimentel 1985) $(\mathrm{a})$

1. Electron scattering

a. Electron spectroscopies (XPS, HREELS, AES)

b. Low-energy electron diffraction (LEED)

c. Electron microscopy

2. Photon scattering (high and low intensities)

a. Spectroscopies (IR, FTIR, Raman, solid-state NMR, ESR, EXAFS, NEXAFS, laser techniques)

b. Grazing angle $x$-ray diffraction

3. Molecule and ion scattering

a. Molecular beam-surface interaction

b. SIMS, ISS

4. Other techniques

a. Radiotracer labeling

b. Mossbauer spectroscopy

c. Thermal desorption

(a) Opportunities in Chemistry, c. 1985 by the National Academy of Sciences, National Academy Press, Washington, D.C.

into practical computer codes requires the active participation of expert software developers. In a rapidly changing computational technology, particularly for high-speed calculations of complex systems, the choice of code architecture is important. Therefore, a strong emphas is will be placed on the computational aspects of the program as well.

The CBD Program expects to support two parallel thrusts: one in conventional chemical catalysis and the other in biocatalysis. The approach described so far is generic and will be valid for both of these thrusts. However, biocatalysis has some unique features that must be addressed separately: the first is that biocatalytic reactions normally take place in a polar environment with the catalyst either in solution or immobilized on a membrane. This is in contrast to the gaseous or non-polar media commonly used in conventional chemical catalysis. The second significant difference is that genetic engineering techniques are frequently used to prepare and modify the structure and activity of biocatalysts. These unique features of biocatalysis require two additional components in the CBD approach:

- Improved synthetic methods - There is a great need to understand how to selectively modify an enzyme to allow it to function in an 
industrial environment. Newly developed methods to execute sitedirected mutations can be applied, for example, to genetically modify the folding pathway and/or the secondary and tertiary structure of active sites. Such mutations could 1) make the enzyme more stable, 2) make the enzyme selective to a particular substrate, or 3 ) result in modifications to the surface electronic structure and a 110 w enzymes to become hydrophobic and to function in nonaqueous solvents. Relevant studies could include techniques to strip away the protein backbone and replace it with a highly stable synthetic backbone, which could result in biocatalysts with desirable properties. New techniques in polymer chemistry could be used to develop methods for synthesizing biomimetic enzymes or active sites.

- Methods to adapt biocatalyst systems to industrial use - Developing generic tools (computational, synthetic, and analytical) will itself have a beneficial impact on biocatalyst development. However, such research does not lead directly to new industrial products or processes. Methods for prediction of macroscale behavior of biocatalysts are necessary so that the submicroscopic and sometimes individual molecule behavior of biocatalysts can be related to the performance of commercial products and processes. The scope of this portion of the program will be to determine biocatalyst effects that may be hidden or nonexistent on a molecular level (e.g., product inhibition, stability in inorganic media, and biocatalyst denaturation by impurities), and to develop generic tools which will predict such behavior.

\subsection{CBD ASSESSMENT METHODOLOGY}

The objectives of this report are to estimate the impact of a successful

CBD Program with respect to:

- developing enabling technologies that will contribute to products and processes with improved energy efficiency

- creating a technology base that is useful to the chemicals industry in improving its productivity and competitive posture.

To achieve these objectives, the methodology used in this study included the following steps:

- Phase I - Three examples of energy-intensive catalytic processes were identified in the chemicals and petrochemicals industries. The potential savings in energy, capital costs, and operating costs achievable with hypothetical new catalysts were identified and the resulting case studies provided quantitative estimates of the potential value of the CBD Program. 
- Phase II - This phase focused on understanding the current industrial approaches to catalyst research, development, and commercialization. As a result of this analysis, generic models describing the types of catalyst research projects commonly supported by industry were developed. These models were used to identify how a successful CBD Program could improve the efficiency of industrial catalyst R\&D.

- Phase III - The results of Phases I and II were reviewed with approximately 20 industrial researchers and $R \& D$ decision makers through one-on-one interviews. The interview process served the dual purpose of educating industry about the CBD Program and obtaining an industrial perspective regarding the program's merits. Subsequently, three workshops were held to discuss the research content of the CBD Program and to develop mechanisms for government/industry collaboration.

The emphasis in this assessment was on collecting the views of a wide assortment of experts with different backgrounds and encouraging them to discuss and debate the CBD concept both in terms of the technology and its potential applications. This dialogue created an atmosphere in which a consensus regarding research priorities and potential impacts ultimately evolved. An important benefit of this approach was the early participation and "buy-in" of many of the key players in industry, the national laboratories, and academia. Indeed, both academic and industrial interest in the CBD Program is high; 16 national laboratory/industry collaborative proposals were submitted. to ECUT.

The following chapters provide detailed descriptions of the results obtained from the tasks included in the three phases. Chapter 3.0 describes the potential impacts of improved catalysts. Chapter 4.0 contains a discussion of the two categories of industrial catalyst R\&D projects. Next, Chapter 5.0 summarizes the results from the industrial interviews and the three CBD workshops. Finally, Chapter 6.0 describes possible mechanisms for government/industry collaboration. 


\subsection{POTENTIAL IMPACTS OF IMPROVED CATALYSTS}

The CBD Program is expected to develop a predictive technology base for catalyst research. The output will be a set of computer codes that researchers can use to "design" new catalysts and catalytic processes. In order to assess the potential impacts of such a program, it is necessary to:

- Establish the impacts of new and improved catalysts on energy efficiency and international competitiveness

- explore the impacts of the program on meeting industrial needs.

This chapter focuses on the first issue and makes some general comments regarding how the CBD Program can contribute to developing the necessary catalyst improvements. Chapter 5.0 addresses the second issue.

As previousiy mentioned, the CBD Program expects to develop two parallel thrusts: one in biocatalysis and the other in conventional (heterogeneous) chemical catalysis. Chemical catalysts are in widespread industrial use and, consequently, the impacts of improvements in such systems are easier to estimate. Biocatalysis, on the other hand, is an emerging field. Currently, there are very few commercial applications, and these are primarily in the pharmaceutical industry. However, biocatalysis has the potential of making major contributions in producing many industrial chemicals. Estimating the potential impacts of an emerging field is usually quite difficult; nonetheless, there are some detailed analyses of the impacts of biotechnology conducted by the U.S. Congress' Office of Technology Assessment (OTA 1981) and the National Academy of Sciences (NAS 1986). In discussing the biocatalys is thrust, we rely heavily on these authoritative studies.

\subsection{BIOCATALYSIS}

Biocatalysis is expected to play an increasingly important role in producing industriat chemicals. Biocatalyzed processes can reduce the nation's dependence on fossil-fuel-based energy sources and greatly accelerate the use of renewable biomass resources as feedstocks. Biocatalyzed synthesis of organic chemicals using biomass feedstocks can replace the currently used petroleum-based starting materials. In addition, since biological processes 
do not require the high temperature and pressure environments of conventional petrochemical processes, energy requirements in biocatalytic reaction schemes are expected to be substantially reduced. The impacts of biocatalytic processes can thus be significant in promoting energy conservation if one considers the following factors:

- Crop land residues such as corn and wheat constitute a potential energy source of 9.0 to 10.0 quad. Forest resources can contribute another 9.0 quad. Biocatalyzed processes can efficiently use biomass resources as feedstocks to produce a variety of chemicals

- The energy conservation potential of biocatalyzed processes in petroleum refining and organic chemicals production is estimated to be 5-7 quad annually (Eberhardt and Keay 1989).

The National Materials Advisory Board (NMAB) of the NAS suggested oxychemicals as one group of products that can be obtained from renewable resources through biocatalyzed processes (NAS 1986). The rationale for concentrating on oxychemicals is based on the high oxygen content (45\%) of the biomass resources. Table 3.1 shows an estimate of the impact on biomass feedstock (corn and collectible cellulose) if all the oxychemical production used such feedstocks, and it is indeed remarkable that oniy $11 \%$ of current corn production and only $3 \%$ of collectible cellulose is enough to meet the entire annual demand for oxychemicals. Clearly, it would not greatly perturb the corn or cellulose supply/demand picture; the current value of these oxychemicals is estimated to be over $\$ 14$ billion in the United States (see Table 3.2), with over 50 billion pounds being produced annually. The oxychemicals constitute $24 \%$ of the top 100 chemicals produced in the United States.

In a 1984 study assessing the potential impacts of biotechnology, OTA predicted more conservatively that markets for chemicals produced through biocatalyzed processes could be as high as $\$ 6.0$ billion by the early 21 st century (OTA 1984). In addition, a potential $\$ 12.6$ billion market for methane produced through genetically engineered processes could also evolve. 
TABLE 3.1. Potential 0xychemicals from Renewable Resources (Source: NAS 1986)

\begin{tabular}{|c|c|c|c|}
\hline Oxychemical & $\begin{array}{l}1979 \text { U.S. } \\
\text { Production } \\
\text { (million lb) }\end{array}$ & $\begin{array}{c}\text { Percent } \\
\text { of the } \\
\text { Corn Crop }(a) \\
\end{array}$ & $\begin{array}{l}\text { Percent } \\
\text { of the } \\
\text { Potential } \\
\text { Cellulosif } \\
\text { Biomass } \\
\end{array}$ \\
\hline Ethylene from ethanol & 29,200 & 36.5 & 9.5 \\
\hline Butadiene from ethanol & 3,600 & 5.3 & 1.4 \\
\hline Industrial ethanol & 1,310 & 0.9 & 0.2 \\
\hline Ethylene glycol & 4,600 & 1.6 & 0.4 \\
\hline Acetic acid & 3,300 & 1.3 & 0.3 \\
\hline Acetone & 2,500 & 2.7 & 0.6 \\
\hline Isopropanol & 1,970 & 2.1 & 0.5 \\
\hline Adipic acid & 1,800 & 1.4 & 0.3 \\
\hline n-Butanol & 560 & 0.6 & 0.2 \\
\hline Propylene glycol & 550 & 0.2 & 0.05 \\
\hline Glycerol & 370 & 0.1 & 0.03 \\
\hline $\begin{array}{l}\text { Butanediol and } \\
\text { tetrahydrofuran }\end{array}$ & 300 & 0.3 & 0.1 \\
\hline Sorbitol & 130 & 0.04 & 0.01 \\
\hline Total & & $\sim 53$ & $\sim 14$ \\
\hline Total excluding ethylene & ut andiene & $\sim 11$ & -3 \\
\hline
\end{tabular}

(a) 7.4 billion bushels, 1979 .

(b) 770 million dry tons, collectible supply.

The overall market for biotechnology-based products could be huge. In a 1985 article in Issues in Science and Technology, Hardy and Glass estimated annual sales of $\$ 1.0$ billion by 1990 , increasing to more than $\$ 100$ billion by the year 2025. These estimates were based on a survey of 50 experts from industry and academia. The industries that will use these products and the year the products are expected to enter the marketplace are shown in Figure 3.1. These optimistic market forecasts prompted industry to invest 
TABLE 3.2. Oxychemical Markets for Innovations in Biotechnology (Source: NAS 1986)

\begin{tabular}{lr}
\multicolumn{1}{c}{ Product } & \multicolumn{1}{c}{$\begin{array}{c}\text { Current } \\
\text { U.S. Value } \\
\text { is million }\end{array}$} \\
\hline Ethanol & \\
Ethylene & \\
Butadiene & \\
Octane enhancer & 6,790 \\
Industrial & 560 \\
$\quad$ Subtotal for ethanol & 380 \\
Ethylene glycol & 9,050 \\
Adipic acid & 1,260 \\
Acetic acid & 1,030 \\
Isopropanol & 620 \\
Acetone & 500 \\
Acrylic acid & 460 \\
Glycerol & 360 \\
1,4-Butanediol & 250 \\
Propylene glycol & 240 \\
Methylethy ketone & 220 \\
n-Butanol & 210 \\
Citric acid & 200 \\
Sorbitol & 190 \\
Propionic acid & 90 \\
Fumaric acid & 35 \\
Total oxychemicals & 25 \\
& 14,180 \\
&
\end{tabular}

close to $\$ 1$ billion in equity for start-up companies and joint R\&D agreements with academia. Most of the funds have been allocated to potentially nearterm products in health care and agriculture.

On the other hand, the chemicals, energy, and pollution-control industries have considered investment in biotechnology to be a high-risk venture. Consequently, they are only directing sufficient R\&D funds to solve the 




FIGURE 3.1. Years by which Biotechnology will have Significant Impact on Particular U.S. Industries (Reprinted with permission from R. W. F. Hardy and D. J. Glass, "Our Investment: What Is at Stake?" ISSUES IN SCIENCE AND TECHNOLOGY, Volume I, Number 3, Spring 1985, by the National Academy of Sciences, Washington, DC.)

problems encountered. However, the enabling technologies required to design and scale up biotechnology processes for these applications are virtually nonexistent.

The role of the Government in supporting biotechnology R\&D programs is also very small because the bulk of the U.S. effort is focused on nearer-term and potentially more profitable pharmaceutical applications. For example, the West German Government has been spending close to $\$ 15 \mathrm{mill}$ ion in biotechnology for industrial chemicals at two research institutes compared to the entire National Science Foundation (NSF) budget of only $\$ 4$ million. Secondly, Japan has established targeted 10-year programs in bioreactors, membrane separations, and biocatalysis. The funding for each is in the range of $\$ 20 \mathrm{million}$ annually, far larger than all the U.S. programs combined. If this trend continues, the United States clearly runs the risk of Tosing its preeminent 
position in biotechnology and allowing our competitors to dominate the estimated $\$ 100$ billion biotechnology markets.

These trends have prompted many recommendations for increased federal support. In an excellent article in Technology Review, George Keyworth strongly recommended the need for developing the required technology base for efficient biocatalyzed processes that industry can "tap into" to develop competitive chemical production schemes (Keyworth 1985). Such a technology base can only be developed through government/industry collaborative ventures. Similar recommendations made by several NAS studies have also suggested the need for a parallel educational program to train researchers in this important area.

The CBD biocatalysis thrust is one of the few U.S. programs clearly targeted to assist in developing biocatalysts for use in producing industrial chemicals. In this aspect, it is a unique program combining the resources of ECUT and industry to promote a critical area that will enhance our energy security as well as international competitiveness. The opinions of industrial decision-makers (obtained during the interviews) strongly suggest that such a program will make significant contributions and is much needed. Details of these interviews are given in Chapter 5.0.

\subsection{CHEMICAL CATALYSIS}

The needs for improved catalysts have been discussed in Chapter 1.0. This section attempts to quantify the impacts of new catalysts by considering three specific energy-intensive processes from the petroleum refining and petrochemicals industries. Catalytic processes are widely used in industry, and it is difficult to realistically estimate the overall impacts of improved catalysts without analyzing each of the applications in detail. Nonetheless, estimates of the impacts have been made based on the case studies discussed below. The estimates are undoubtedly optimistic, but they do provide insights into the magnitudes of energy and cost savings that are possible with vastly improved heterogeneous catalysts for existing petroleum refining and petrochemicals processes. The three examples used for the case studies were: 
- Fluid Catalytic Cracking ( $F C C$ ): Catalytic cracking breaks down the high-molecular-weight hydrocarbons from heavy petroleum fractions to lighter compounds contained in gasoline. Approximately one-third of the total petroleum feedstock to a refinery is processed by catalytic cracking, making it second only to hydrotreating as the largest catalytic refining operation in process volume.

- Alkylation: The alkylation reactions combine mixed butylenes and/or propylenes with isobutane to form highly branched octane enhancers for gasoline. The process volume is small when compared to other refining operations, but the energy consumption per pound of alkylate produced is high.

- Styrene Production: Table 3.3 lists the feedstock and process energy required to produce commodity chemicals from petroleum feedstocks. Clearly, styrene is the most energy-intensive, consuming about $10 \%$ of the feedstock energy for the chemicals industry and close to $1 \%$ of the process energy.

To estimate the potential impacts of improved catalysts for each of the three cases, the state-of-the-art process is compared to a process designed around an ideal catalyst. Characteristics of the ideal catalysts are estab1 ished from thermodynamic limits and interviews with industrial catalyst experts. The results of the case studies are summarized in the following sections. For a detailed analysis of the case studies, the reader is referred to the Pacific Northwest Laboratory (PNL) report entitled Energy and Economic Savings from Improved Catalysts.

\subsubsection{Fluid Catalytic Cracking}

Almost one-third of a typical refinery output is processed by catalytic cracking. The primary reactions that occur in the catalytic cracker can be described as:

Paraffins $\rightarrow$ Paraffins + Olefins

Alkyl Naphthenes $\rightarrow$ Naphthenes + Olefins

Alkyl Aromatics $\rightarrow$ Aromatics + 0lefins

(a) This PNL report was prepared for the Energy Conversion and Utilization Technologies Division, Office of Energy Utilization Research, Conservation and Renewable Energy, DOE, by D. L. Brenchley et a1., March 1986. 
TABLE 3.3. 1983 Energy Requirements for Major Chemical Products ( $10^{13}$ Btu/yr)

\section{Chemical}

Styrene

Vinyl Chloride

PVC

PET

Nylon 6,6

Phenol/acetone

Polystyrene

Ethylene Glycol

HMDA

Nylon 6

Vinyl Acetate

Adipic Acid

Caprolactam

PAN

Urea-Formaldehyde

Propylene glycol

Acetic Acid

(from acetaldehyde only)

Acetic Anhydride

(from acetic acid and ethylene)
Energy Requirements

\begin{tabular}{|c|c|c|c|}
\hline Feedstock & Process & Total & Reference \\
\hline 20.08 & 2.70 & 22.78 & $a, d$ \\
\hline 16.31 & 3.09 & 19.40 & $a, b$ \\
\hline 14.72 & 2.74 & 17.46 & $a, b, j$ \\
\hline 12.18 & 4.44 & 16.62 & $a, b, c, e$ \\
\hline 5.63 & 8.36 & 13.99 & $a, b, c, e$ \\
\hline 10.55 & 2.99 & 13.54 & $a, d, e$ \\
\hline 9.19 & 2.00 & 11.19 & $c, d$ \\
\hline 9.26 & 1.55 & 10.81 & $a, b$ \\
\hline 3.99 & 2.46 & 6.45 & $b, c, e$ \\
\hline 2.05 & 4.27 & 6.32 & $c, e, f$ \\
\hline 3.76 & 2.29 & 6.05 & $a, c, f$ \\
\hline 2.27 & 3.76 & 6.03 & $a, b, e, i$ \\
\hline 2.05 & 2.19 & 4.24 & $c, e, f$ \\
\hline 2.74 & 1.65 & 4.39 & $b, c$ \\
\hline 2.08 & 1.33 & 3.41 & $a, c, e, k$ \\
\hline 1.80 & 0.79 & 2.59 & $a, b$ \\
\hline 1.47 & 0.91 & 2.38 & $a, f, g$ \\
\hline
\end{tabular}

0.40

0.33

0.73

$a, f, g$

0.004

0.001

$0.005 \mathrm{~b}, \mathrm{~h}$

Note: All energy converted to primary fuel equivalent. Information from the cited sources was used to calculate these values.

a. Chemical and Engineering News (1984).

b. Gaines and Shen (1980).

c. ACS (1984).

d. Chemical Engineering (1983).

e. Hamel, Brown and Nedman (1979).

f. Data Resources (1978).

g. A. G. Bayer Company (1979).

h. Greek (1984).

i. McKetta (1977).

j. EEAI (1983).

k. Shreve and Brink (1977). 
The cracking reactions are endothermic (require heat); the process operates at $400^{\circ} \mathrm{F}$ to $500^{\circ} \mathrm{F}$. The common feedstock for the catalytic cracker is vacuum gas oil boiling in the range of $650^{\circ} \mathrm{F}$ to $1000^{\circ} \mathrm{F}$.

The typical product slate depends on the refinery goals and the composition of the available feedstock. The common practice is to obtain 50 to 70 vol \% gasoline (hydrocarbons boiling in the $100^{\circ} \mathrm{F}$ to $440^{\circ} \mathrm{F}$ ) and 15 to 25 vol \% light cycle oil ( $(\mathrm{CO})$. The remainder is heavy cycle oil (HCO), which is sold as No. 6 heating oil for commercial and residential space heating. The goal of most refineries is to maximize the gasoline yield from the catalytic cracking process, with the efficiency of the catalyst as the limiting factor. Thus, in this case study, the ideal catalyst was defined as having two primary characteristics:

1. It would produce gasoline with close to a $100 \%$ yield. The amount of coke or HCO produced would be just enough to provide the heat required for the endothermic catalytic reactions.

2. The catalyst would be unaffected by nickel or vanadium and could maintain its high selectivity for cracking reactions to produce gasoline.

The primary advantages from such an ideal catalyst would include the following:

1. Lower production of carbon and tar deposits would occur, resulting in decreased requirements for catalyst regeneration.

2. Fractionation requirements would be minimized because gasoline would be the primary product.

3. Feedstock requirements per unit of gasoline produced would be drastically reduced.

4. Heavier crudes containing metal impurities such as nickel and vanadium could be used without the need for additional catalysts and/ or metal deactivators.

If such an ideal catalyst were introduced in a state-of-the-art FCC unit, such as the Reduced Crude Conversion (RCC) process developed by Ashland Petroleum, it could result in capital cost savings of $\$ 34$ million and energy savings of 2.66 trillion Btu/year for an FCC unit producing 19,950 barrels per stream day (BPSD) of gasoline. These estimates were obtained by conducting 
detailed material and energy balances of the RCC process with and without the ideal catalyst. The potential capital cost and energy savings are quite impressive. However, there are no savings in operating costs; in fact, operating costs increase slightly since byproduct credits for LCOs and HCOS are not available.

If an ideal catalyst were available, it would be readily accepted by the refining industry, resulting in cumulative energy and capital cost savings of as much as 8.0 quad and $\$ 23$ billion, respectively. Obviously, the impact of an improved $\mathrm{FCC}$ catalyst on the petroleum refining industry is high. However, we must emphasize that the ideal catalyst described in this case study needs to perform very close to the thermodynamic limits. Generally, it is extremely difficult (if not impossible) to develop catalysts with such a high level of performance. The estimates in energy and capital cost savings established here are, therefore, very optimistic. Nonetheless, it is clear that improved catalysts capable of increasing gasoline yields will have a major impact. It is not unreasonable to assume that such catalyst improvements will occur and that the CBD Program can make a direct contribution in that desirable effort.

\subsubsection{Alkylation}

In petroleum refining, alkylation is the process that combines mixed butylenes and/or propylene with isobutane to form highly branched, highoctane gasoline components; either sulfuric acid or hydrofluoric acid is the catalyst of choice for the alkylation reaction. Both catalysts operate on the same feedstock to produce virtually the same product slate. However, the utilities consumption for the sulfuric acid process is much lower, so it is used as the state-of-the-art process for this analysis.

The product slate from the alkylation reaction consists of isooctane and isoheptane, with isooctane being the preferred product. Other byproducts include isopentane, isohexane, propane, and tar. The yield of the alkylate product is about $80 \%$ of the feedstock weight, which leaves little room for improved catalytic efficiency. Therefore, the driving force for new catalysts in this application is not efficiency, but the need for a solid catalyst which could be packed in a fixed-bed reactor. 
The catalyst must maintain its selectivity for alkylate at higher temperatures and must not require extensive regeneration and/or replacement.

Such a catalyst does provide many benefits compared to the currently used acid catalysts. These include all the issues relating to handling and disposing of large volumes of concentrated corrosive acids, as well as the extensive refrigeration requirements of the sulfuric acid-catalyzed alkylation process. In the absence of refrigeration, the product mix is dominated by an unwanted polymer product instead of the alkylate.

The ideal alkylation catalyst would probably not change either the feedstock quantities or the yield of the alkylate product. However, as it maintains its selectivity at higher operating temperatures, the new catalyst would greatly modify the process design. A conceptual process design for an alkylation unit using an ideal catalyst is shown in Figure 3.2. In this design the catalyst is packed in heat exchanger tubes and the feed circulation is through the tubes. The product stream goes to a fractionation column where propane is condensed with cooling water and the unreacted isobutane is recycled. The alkylate is drawn off the bottom of the fractionation column.

When compared to the conventional Stratco process with sulfuric acid catalyst, the main advantages of this ideal process are reduced capital costs and process energy savings. A comparison of the material and energy balances indicates that for an equivalent plant, the ideal process could save $\$ 6$ million in capital costs and $950 \mathrm{Btu} / 1 \mathrm{~b}$ of alkylate produced. The energy savings arise from eliminating all the refrigeration and compression requirements of the Stratco process. These estimates were for a plant producing 3,500 BPSD alkylate products. Substantial operating cost savings in the range of $\$ 3.00$ / barrel are also realized.

The petroleum refining industry has been interested in fixed-bed alkylation catalysts for years, but no such catalyst has yet been discovered. Nonetheless, there are no known technical reasons why such a catalyst cannot be found, and it is to be hoped that the CBD approach will someday contribute in that search. Clearly, the potential benefits warrant an aggressive search for such a catalyst. 


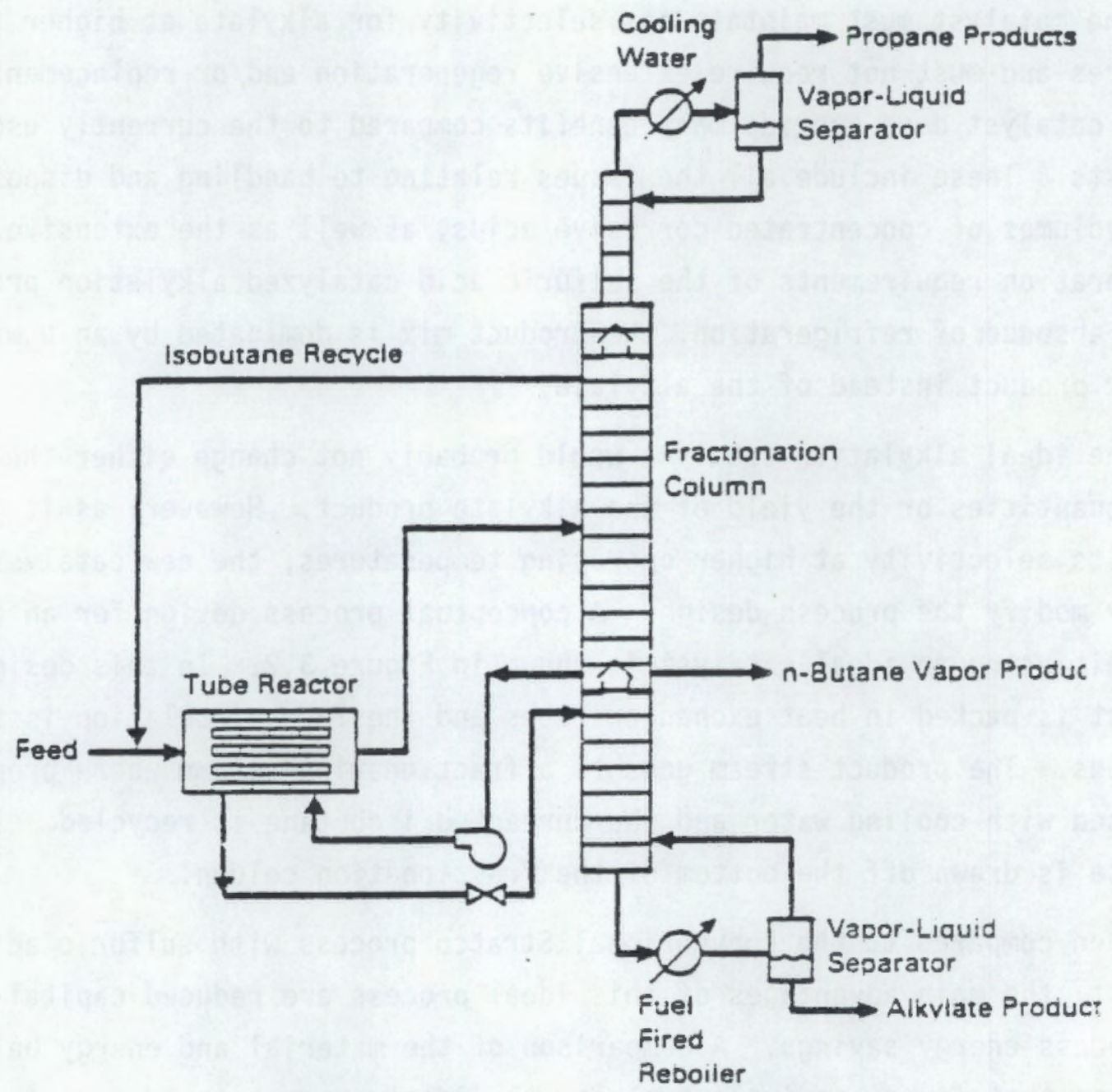

FIGURE 3.2. Ideal Alkylation Process (Source: Energy and Economic Savings from Improved Catalysts, PNL Report, D. L. Brenchley et al., March 1986)

\subsubsection{Styrene Production}

Styrene is produced in a two-step process: the first is the catalytic alkylation of benzene with ethylene to produce ethylbenzene. Aluminum chloride with an $\mathrm{HCl}$ promoter catalyzes the exothermic alkylation reaction. The conversion efficiency is only $40 \%$ for benzene. The ethylbenzene product is separated in a complex process and subsequently undergoes catalytic dehydrogenation to produce styrene. The efficiency of converting ethylbenzene to styrene in the endothermic dehydrogenation step is also approximately $40 \%$. 
The ideal catalyst considered in this case is expected to allow benzene and ethylene to react in a single-step process to produce styrene. The equilibrium constant of the reaction allows us to predict that if liquid benzene reacts with gaseous ethylene at $200^{\circ} \mathrm{C}$ and 18 atmospheres pressure and the byproduct hydrogen is simultaneously removed, the process should thermodynamically lead to the complete conversion of the reactants to styrene. The catalyst must, therefore, demonstrate the following characteristics:

- It must promote the conversion of liquid benzene and gaseous ethylene to styrene with close to $100 \%$ selectivity.

- It must demonstrate a 1-year life without any regeneration.

- It must be in a form that can be immobilized on membranes without any loss in activity.

Based on these characteristics, a conceptual design for a novel membrane reactor was developed for styrene production. The schematic of a $700 \mathrm{million}$ $1 \mathrm{~b} / \mathrm{yr}$ styrene plant using the hollow-fiber membrane reactor is shown in Figure 3.3. This design concept provides significant advantages over the conventional process including the following:

- Capital cost savings would approach $80 \%$.

- Operating costs could be reduced by $18 \%$.

- Feedstock energy consumption would be reduced by $8 \%$ and process energy savings would approach $12 \%$.

\subsection{SUMMARY OF CASE STUDIES}

The three case studies show that revolutionary improvements in catalyst properties, coupled with major process redesign, can have tremendous impacts in improving energy efficiency and reducing the capital and operating costs of important industrial processes. There are many other examples that could be cited. The PNL study predicted that such improvements, when applied across the board to catalytic processes in the chemicals, petroleum refining, and petrochemicals industries, can generate potential savings of $\$ 31$ billion in capital costs and $\$ 69$ billion in operating costs over a 15 -year period. The 


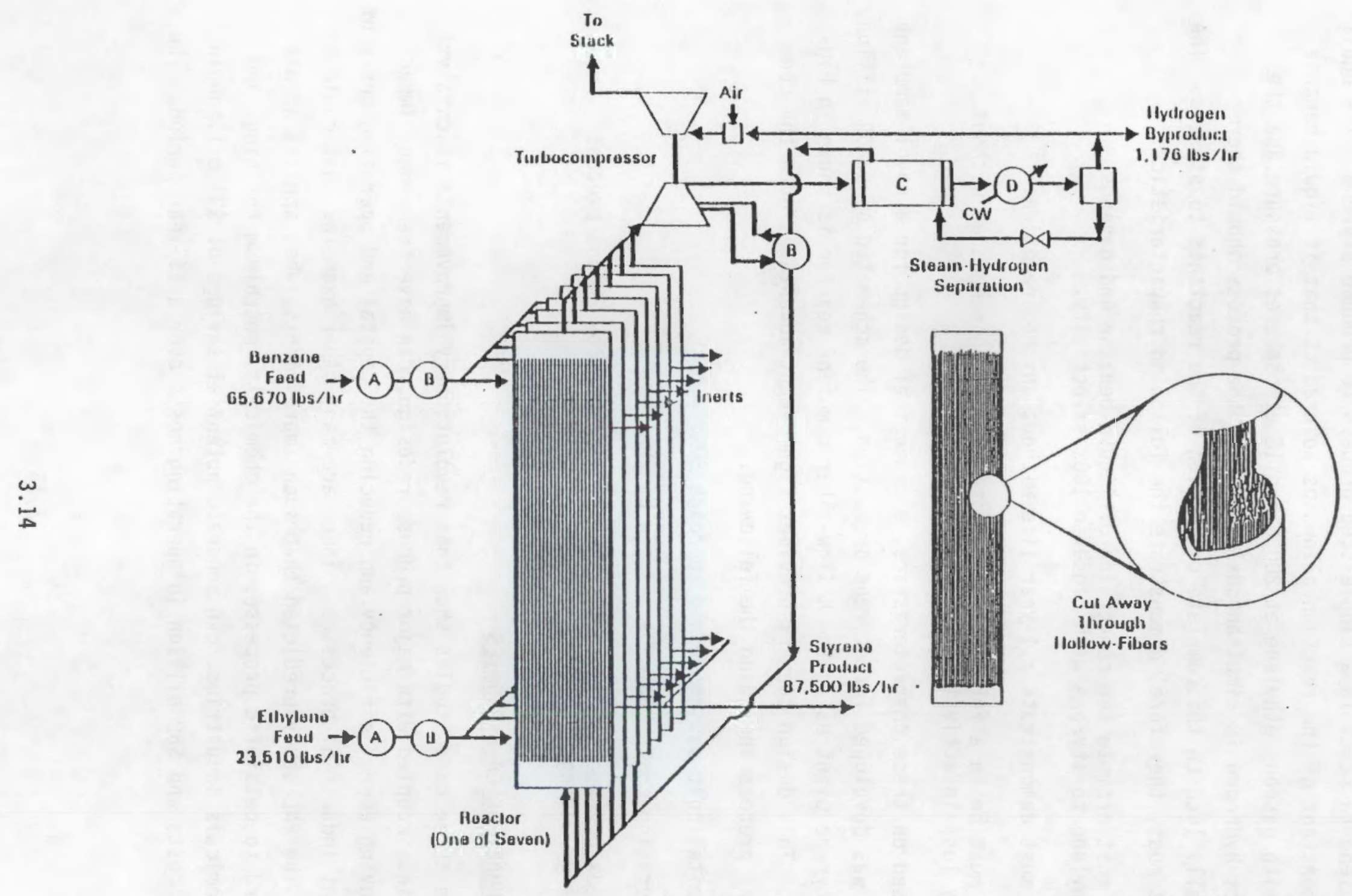

FIGURE 3.3. Ideal Styrene Process Schematic (Source: Energy and Economic Savings from Improved Catalysts, PNL. Report, D. L. Brenchley et al., March 1986) 
parallel energy savings are expected to be in the range of 9.0 quad of feedstock energy and 8.0 quad of process energy. While these numbers are very impressive, it is important to note that the assumptions underlying these estimates are extremely optimistic. Nonetheless, they do emphasize that quantum improvements in catalyst performance can have very significant effects on the nation's energy security and industrial competitiveness.

Clearly, the advantages demonstrated in these case studies are worth pursuing. However, the requirements placed on the "ideal" catalysts are extremely demanding. They are not incremental improvements of existing catalysts, and they involve high-risk novel approaches to both the catalysts and the process development efforts. Industry has not usually supported such high-risk, technology-driven projects. This is understandable considering industry's needs to maintain a continuous growth in profitability based on incremental improvements in existing product portfolios.

The chemicals industry, however, does support a robust R\&D program. They recognize the need for continuous improvement of their technologies. It is this aspect that has kept the industry on or near the top in an extremely competitive global marketplace. Chemical industry executives are fully cognizant of the need for research that will introduce revolutionary improvements in current processes, and they are willing to participate with ECUT in building the technology base for such process development efforts. This was made abundantly clear in the interviews and in the workshop discussions held in 1989 that defined the CBD research agenda (Fassbender et a1. 1990). 



\subsection{INDUSTRIAL CATALYST RESEARCH}

Industrial catalyst R\&D projects are commonly classified into two categories. The first category, which encompasses the most predominant type of projects, involves the incremental improvement in the performance of existing catalysts in response to market pressures. It also includes research to customize a catalyst to meet the specific needs of a current user. R\&D projects in this category are initiated in direct response to market needs and are usually referred to as "market-driven."

The second category involves the development and exploitation of totally new classes of catalysts resulting from major research breakthroughs. These projects tend to be high-risk and long-term in nature. However, if they are successful, they can also generate a much higher rate of return. Projects of this type are usually described as "technology-driven."

Although most industrial concerns try to maintain a balance between the two types of projects, the emphasis is always on the shorter-term marketdriven projects. Approximately $10 \%$ to $20 \%$ of the R\&D resources of a catalyst development company are usually committed to technology-driven projects, and the remainder to short-term market-driven projects to either improve or customize catalyst performance in terms of yield and/or specificity.

\subsection{MARKET-DRIVEN PROJECTS}

Very few industrial catalyst research programs are aimed at developing new catalysts or new catalytic reaction schemes. Instead, most are targeted toward the incremental improvement of the performance of catalysts for existing processes. A typical example is the acrylonitrile catalyst developed at SOHIO (current7y British Petroleum). When the catalytic process was first introduced commercially, the yield of the desired product was only $48 \%$. However, it was still attractive when compared to the existing conventional process. During the next two decades, the consistent research effort at $\mathrm{SOHIO}$ succeeded in improving the yield to over $84 \%$. This major effort was necessitated by the demands of the competitive marketplace and the company's desire to improve its market share. Although the initial discovery was clearly 
technology-driven, the subsequent methodical improvement of the catalyst performance was definitely the result of market forces.

Another type of market-driven catalyst research arises from the catalyst supplier's increasing need to customize catalyst systems to address the needs of specific customers. This is a clear trend in the catalyst industry. Catalyst users have reduced their research efforts and are increasingly relying on the suppliers to undertake the entire burden of customizing a catalyst for their specific requirements. For example, Calsicat (a unit of Mallinckrodt) estimates that $40 \%$ of its catalyst sales are custom-made. The German firm Degussa claims that virtually all of its catalyst business is in customized systems.

Regardless of the driving force, most market-driven catalyst development programs follow the steps shown in Figure 4.1. Such programs usually build on the experimental databases already available at industrial catalyst research groups. Typically, 90\% of research ongoing at major catalyst development companies falls in this category. At one major catalysis research facility that PNL visited, our interviews indicated that of 20 or 21 ongoing projects, approximately $18 \mathrm{fa} 11$ in this category, while the remaining 2 or 3 are directed at potentially new product lines.

A market-driven need either from a company's own plant or from that of an existing or potential new customer triggers the process depicted in Figure 4.1. The first step in the process is to set targets for performance improvements. For projects that support existing product lines, most of the knowledge resides with in the company, including some empirical models for the search for improved catalysts. Step 2 is to develop the catalyst concept and pick classes of materials for screening. The third step is to screen candidate materials and identify the most promising ones. Presently, this type of screening is conducted very efficiently in micro-reactors coupled to gas chromatographs.

At this point, a preliminary cost/benefit analysis is performed and a go/no-go decision is made. If the cost/benefit analysis yields favorable results, then work progresses to the operation of a laboratory prototype reactor--a reactor used to obtain data on the reaction kinetics, fluidization 


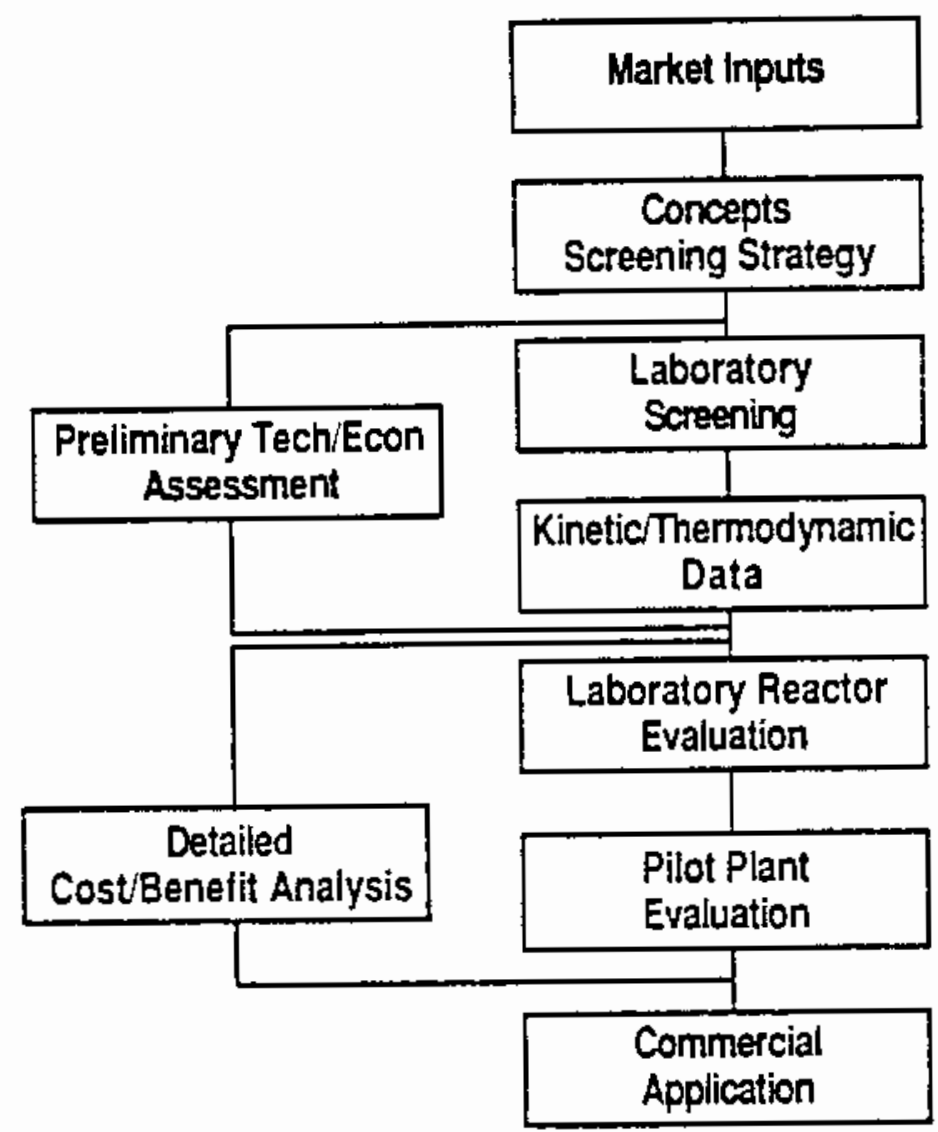

FIGURE 4.1. Flow Diagram for Market-Driven R\&D Projects

properties, and the lifetime of selected materials. The next step is to design a pilot plant and establish the catalyst manufacturing sequence. For incremental improvements, such a step would include minor modifications to the existing pilot plant and conmercial-scale reactors. The cost associated with such modifications is small.

Scale up to pilot plant and commercial level occurs rapidly if the performance, cost, and lifetime of the catalyst are judged to be adequate. The production line to manufacture the modified catalyst could involve modification of an existing line or construction of a new one, depending on how different the new catalyst system is compared to the one it is replacing. Traditionally, the equipment required to manufacture most catalysts is similar, and production lines can be easily modified with minimal cost to produce different catalysts. 


\subsection{IECHNOLOGY-DRIVEN PROJECTS}

Technology-driven projects result from major breakthroughs in research; often the breakthrough appears to be a random event. Mobil's methanolto-gasoline (MTG) technology, which uses the zeolite (ZSM-5) catalyst, is one such example (Meisel 1988). Two groups at Mobil working independently made different observations that resulted in this important discovery. One group trying to convert methanol with ZSM-5 to other oxygen-containing compounds produced hydrocarbons instead. The other group was trying to alkylate isobutane with methanol using ZSM-5 and obtained a mixture of aromatics and paraffins boiling in the gasoline range. These two parallel observations led to the realization at Mobil that apparently a new catalytic reaction had been discovered.

The 2SM-5 zeolite catalyst was capable of converting methanol to gasoline. However, the road to a commercial process was still a long and difficult one. The risk associated with a long-term project like this was high even for Mobil. It required the active participation of the Energy Research and Development Administration (ERDA, subsequently DOE) and two decades of extensive research and engineering development for a commercially viable process to be developed. The first MTG plant using this technology was brought online in New Zealand in 1986. This example illustrates the complexity and the risks involved in supporting technology-driven projects and provides insights into why industry supports few such projects.

The typical steps involved in developing a technology-driven project through the research phase into a commercial product or process are shown in Figure 4.2. The project is usually initiated based on an attractive hypothesis or a chance observation of a researcher. It is common to see such a project at a corporate research laboratory with only one researcher and a technician working on it. Once a "discovery" is made, i.e., a promising system is identified, a preliminary market and cost assessment is done. Based on this assessment, if the decision is to pursue the project, research is conducted on kinetics and reaction mechanisms of promising catalytic materials. The screening of materials is pursued with vigor to identify candidates with 


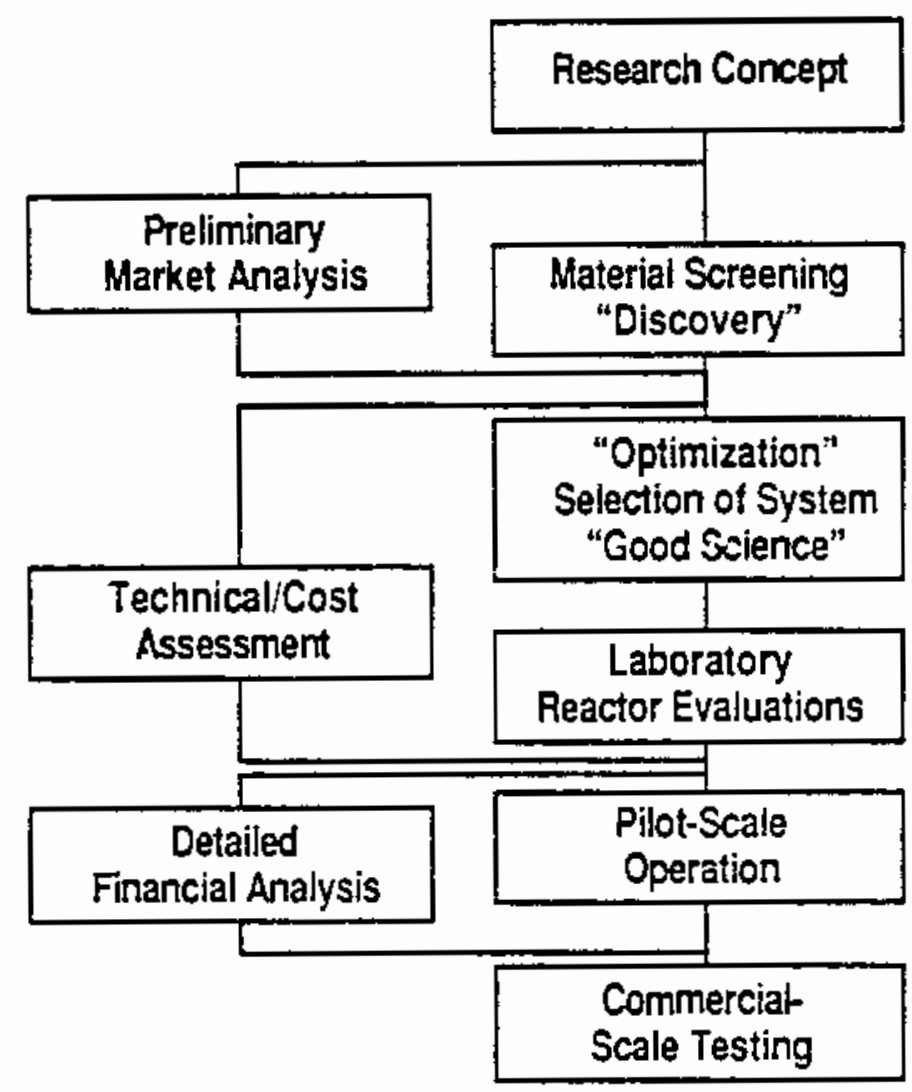

FIGURE 4.2. Flow Diagram for Technology-Driven R\&D Projects

optimal performance. Finally, a group of candidates is identified, and technical and economic assessments are done.

If the results are favorable, a laboratory prototype reactor is operated in order to obtain data on the reaction kinetics, fluidization properties, and the 1 ifetime of selected materials. These data are used to design a pilot plant and establish the catalyst manufacturing sequence. The company then begins making significant capital and manpower commitments, since the new catalyst system could require significant changes in reactor design and operation or in the process streams. Next, a cost/benefit analysis for a pilot plant operation is performed. With favorable results, the decision is made to construct and operate a pilot plant. The smooth operation of a pilot plant is followed by the design and costing of a commercial-scale plant. If the 
capital and operating costs appear to be favorable and the discounted cash flow rate-of-return is attractive, then the commercial-scale plant is constructed and operated.

The primary difference between the approaches shown in Figures 4.1 and 4.2 is that the former is market-driven, whereas the latter is technology-driven. In the former case, an external stimulus, such as a request from an operating unit, usually prompts initiating a development program. The market need for the project is therefore clearly defined. In the latter case, the project is usually initiated as a researcher's idea, and its potential market is less clearly defined. In both cases, however, there are two distinct phases in industrial catalyst research programs: exploratory research and pilot plant operation.

Exploratory research includes the work during the laboratory evaluation phase, which is transferred to the pilot plant phase if it is successful. For incrementa] improvements in catalyst performance, most of the effort is usually in the exploratory phase (about 2 years). Enough information is available on such systems for companies to predict the behavior of a catalyst at the commercial level from data obtained in the exploratory phase, a point made repeatedly during our interviews.

In the case of a new cataiyst, much more data is needed to justify pilot plant operation. Consequently, the project remains in the exploratory research phase longer ( 5 years versus 2 years for incremental improvements). The operation of a pilot plant for a new catalytic process involves significant costs and associated risks because there is a greater need to establish performance and life of a new catalyst at the pilot plant level before it is scaled up to the commercial level. Thus, several industrial research managers estimated that a research effort to develop a new methanol oxidation catalyst could take approximately 10 years. It would be in the exploratory phase for 5 years (approximately 10 man-years) costing an estimated $\$ 1.25$ million. The pilot-scale operation could last about 2 years, with an approximate cost of $\$ 5$ million, and a conmercial plant would cost about $\$ 100$ million. 


\subsection{CATALYSI SCREENING}

Regardless of whether the catalyst research project is technology- or market-driven, it is stil1 primarily a trial-and-error process. The process is characterized by an inordinate focus on the screening of a variety of materials for catalytic activity. In a recent article in Research and Development, R.A. Gardner says that almost all commercially available catalysts have been discovered by trial and error (Gardner 1988). Such an argument is obviously an oversimplification. Nonetheless, it does highlight the fact that catalys is is a poorly understood phenomenon and that most catalyst discoveries and/or improvements occur through laborious screening of many potential materials. For example, in the R\&D phase of automobile catalytic convertors, General Motors (GM) alone had tested over 1500 formulations submitted by some 82 companies (Hegedus 1980). The overall effort included $5000 \mathrm{GM}$ employees, and approximately 22 million test-miles were driven prior to the practical use of such a convertor. This example illustrates the complexity of the problem and provides a fascinating glimpse of the magnitude of effort required to deve op totally new catalyst systems.

Although screening of catalytic materials can be time-consuming and labor-intensive, recent advances in the catalyst industry have succeeded in reducing the time and effort that must be devoted to screening. Microreactors coupled to gas chromatographs operating under computer control have significantly reduced the time and effort required in catalyst screening. Despite the progress, it still is a significant component of catalyst research. Technologies that will allow further reducing or possibly even eliminating the screening requirement are very much desired by industry, and CBD may prove to be one such technology. 


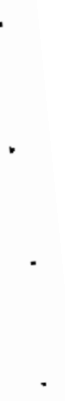




\subsection{RESULTS FROM INTERVIEWS AND WORKSHOPS}

This chapter describes the results of the industrial interviews with catalysis R\&D managers and research scientists/engineers at nine organizations in late 1988 and early 1989. In addition, the chapter contains summaries of the proceedings of the first two CBD workshops that were held in the summer of 1989. The third workshop is discussed in Chapter 6.0.

\subsection{INDUSTRIAL INTERVIEWS}

Discussions with R\&D managers at major firms in the chemicals, petroleum refining, petrochemicals, and biotechnology industries were used to generate much of the desired information regarding the potential magnitude of CBD impacts. The interviewees were reluctant to disclose detailed information about their companies' catalyst R\&D programs, and it was agreed that we would not report proprietary catalyst development data, but rather we would try to verify generic data based on their experiences.

Our overall objective was to analyze the potential impacts of the CBD Program on industrial catalysis research. Our efforts were organized into three tasks:

1. Characterize the steps in the traditional catalyst development process and estimate the time, cost, and probability of success for each step. Also, identify how the CBD approach will be used to complement or replace the traditional catalyst development process.

2. Interview industrial R\&D managers to verify the information developed in Task 1.

3. Arrange a workshop with participants from DOE, the national laboratories, universities, and industrial catalyst developers to discuss the findings of Tasks $I$ and 2 .

Our approach was to first develop a framework for the traditional catalyst R\&D process and review and optimize this framework with experts from national laboratories, academia, and industry. Next, we tried to identify potential areas of cost savings and productivity improvements that the CBD approach offers compared to the traditional process. At this point, we began the interviews to confirm with industrial researchers the steps in the 
traditional catalyst development process and their relative costs. Another objective of the interviews was to familiarize industry with the CBD approach and present them with our estimates of the potential impacts. We solicited their opinions regarding the validity of our estimates, and attempted to get specific answers for specific catalyst systems. Also, we asked them to estimate what savings could have been achieved for some already-developed catalysts if the CBD approach had been available.

Through the interviews, we attempted to gain a thorough understanding of the benefits of the CBD approach and how these benefits can be realized. In addition, we attempted to gain an understanding of the barriers to implementing the CBD approach in an industrial setting. Special emphasis was placed on the role of corporate decision-making on scale-up and commercialization. The questionnaire used in the interviewing process is shown in Table 5.1. Interviews with the companies (referred to as Companies A through I) are described in the following subsections.

\subsubsection{Company A}

Company A scientists with whom we met were rather skeptical about the potential success of CBD. They did not see how DOE could develop what would be perceived by industry as a useful tool, given that the necessary data is proprietary and industry will not make it readily available to DOE. The CBD Program clearly will require access to the substantial databases existing in industrial research laboratories.

The participants in this discussion generally felt that all landmark breakthroughs in catalys is have been unexpected. A major discovery certainly cannot be predicted, but perhaps incremental improvements are predictable and, thus, may benefit from a CBD-type approach. There was some concern that CBD models will be based on conventional wisdom at the time and since breakthroughs usualiy require departure from conventional thinking, these models may indeed be obstacles to exploring unconventional ideas.

CBD can be visualized as a framework in which to design experiments, and it is Company A's perception that the inventive people will change the framework often. As the catalysis expertise grows, CBD will become more and more 


\section{TABLE 5.1. Questionnaire for Interviews}

1. What types of catalysts is your company developing? What portion of your R\&D effort is based on the need to improve existing catalysts, and what portion goes for exploring novel catalytic processes?

2. It is difficult to discuss a generalized cost of catalyst research. However, based on your experience in this industry, could you try to estimate the approximate cost of each step involved in industrial catalyst development efforts?

3. From your personal experience with a specific catalyst development effort in the past, could you provide us with estimates of elapsed time, level of effort (person-years), and cost associated with the various phases of that development effort?

4. What was the range of catalyst formulations typically tested in the laboratory before successful candidates for bench-scale testing were determined? What was a typical number of formulations to undergo bench-scale testing? Once bench-scale tests were completed, how many formulations became candidates for large-scale manufacture and/ or utilization? What was the success rate for these products in the market place?

5. If a CBD technique had been available to you in the catalyst development effort discussed above, what would the qualitative benefits have been?

6. Given that a CBD technique might allow researchers to more accurately predict the catalytic properties of materials before laboratory and bench-scale testing, to what extent could CBD conceivably reduce the number of formulations to be tested in the laboratory at the bench scale?

7. What might the magnitude of the resulting time and cost savings be during the laboratory research phase? During bench-scale testing? What are the reasons why these savings would occur?

8. Do you agree that the CBD approach might result in products with improved performance and quality? If so, to what extent would CBD increase the success rate and market penetration of resulting products (either the catalysts themselves or the products produced by the catalysts) in the world marketplace?

9. Do you think that the CBD approach, if successful, will be beneficial to the international competitiveness of U.S. industry? If yes, how? 


\section{IABLE 5.1. (contd)}

10. Are you aware of any techniques that are similar to the CBD approach that industry is currently supporting on their own? If not, why not?

11. Do you think it may be difficult to get industry to accept the CBD approach? If so, why and what results and activities would industry need to reduce this barrier?

12. The Energy Conversion and Utilization Technologies (ECUT) Division of the U.S. Department of Energy's (DOE) Office of Conservation and Renewable Energy supports high-risk, high-payoff generic applied research that is of great interest to industry. Do you have any suggestions for future government/industry interactions to improve the utility of $C B D$ research results for U.S. industry?

13. What should industry's role be in supporting a program such as CBD? At what stage of R\&D would industry consider joint support with DOE in this program?

14. In what areas of catalysis or biocatalysis research (e.g., poisoning, undesirable interactions, topological effects) would the development of reliable models to predict atomic and molecular behavior be most desirable in the future?

15. Are you currently considering R\&D to develop industrial biocatalysts? If so, what is your current mix of conventional catalysis and biocatalysis activities? What do you think your mix might be in ten years?

of an expert system. That, indeed, is the goal of the CBD approach. However, it is difficult to construct an expert system in catalysis research, especially when the experts do not a]ways agree on the reaction mechanisms. Also, it is not uncommon for a general theoretical framework for a particular catalytic process to be developed some 20 years after the initial catalyst discovery.

The participants were emphatic in their opinion that academic researchers are generally unaware of commercially viable catalyst formulations and the preferred operating conditions of industrial catalytic systems. Thus, academia does not have a realistic understanding of many proprietary catalysts, and they are not in a position to contribute much in the area of cataiyst development. A collaborative effort between industry and academia is needed. 
However, they feel that some excellent work is ongoing at Stanford, Northwestern, Delaware, and Berkeley. Most of this research involves surface science technique development, as opposed to searching for new catalysts or understanding the reaction mechanisms of existing catalysts. Such activities were strongly endorsed by the participants. This view is fully consistent with the ECUT approach, where DOE will undertake the support of generic applied research and rely on industry to use the results to develop proprietary products and processes.

About $40 \%$ of Company $A^{\prime} s$ budget is spent on supporting existing product lines, which they call manufacturing technical services and marketing technical services. The other $60 \%$ is spent on catalyst improvements. The key question that determines whether new product exploratory research is funded: "Is there a profit to be made?"

There are about 20 catalysis programs ongoing at any point in time in Company A's Catalysis Department. The majority (17-18) are incremental improvements to existing catalysts, while the remaining 2-3 are new product lines. They also produce "step-out" products as spin-offs of their research. In addition, they license technologies to others.

Company A scientists do anywhere from a few hundred to more than a thousand bench-scale tests before going commercial with a catalyst. Once a catalyst gets to the pilot plant stage, it usually goes commercial. Company $A$ would be willing to go from bench-scale tests to a commercial plant in many cases, but often the pilot plant serves to convince the customer that the data is credible.

In summary, Company A believes that CBD would elevate the degree of understanding, but not necessarily reduce the number of catalyst screenings. Tests could be made on more advanced formulations. The impact would be on the quality of the screenings as opposed to the quantity.

\section{1 .2 Company B}

Most of Company $B^{\prime}$ s catalysis research was for the chemicals industry. Their opinion was that the efficiency of catalyst screening has increased at 
least a thousand-fold with the advent of the micro-reactor. It used to take 4-5 weeks to get the results of one screening run, whereas now it only takes a day to get the same results.

It takes many years of experience to understand catalysis. Nonetheless, anything that one can do to help "design" a catalyst is better than just trying one formulation after another. The overall objective of the CBD Program was considered to be desirable. Company $B$ saw the value of CBD for the type of catalyst research where a company is trying to develop a totally new catalyst and a new catalytic process. They felt that high-risk, long-shot catalytic routes for bulk industrial chemicals production is an area where CBD can be immensely helpful in providing directions to the scientists on the nature of materials that are worth examining further. This would impact both the quantity and the quality of the catalyst screening process.

Catalyst research has been more of an art than a science, with most discoveries being made by accident, relying on a purely trial-and-error approach. The fundamental mechanisms were determined by others at later times. For example, Company $B$ developed the acrylonitrile catalyst in collaboration with a university by accident. However, much good science took place after the initial discovery was made. Thus, Company $B$ has been able to improve the yield of their acrylonitrile catalyst from $48 \%$ to $84 \%$ over six generations of continuous improvements in catalyst formulations.

We asked Company $B$ whether the acrylonitrile catalyst development process would have been significantly different if CBD had been available at the time. They felt that it is not prudent to think of CBD as a way of "shortening the cycle;" instead we should realize that CBD will allow researchers "much better leads," resulting in "better" catalyst discoveries. The major impact of CBD will probably be in solving the very difficult problems in high-payoff, lowprobability catalytic processes. CBD will contribute by allowing researchers to formulate hypotheses and by providing better experimental leads, especially unusual ones that scientists skilled in the area would not think of. CBD would be used to enhance the creative process more than to save time.

To design a meaningful CBD Program, it was felt that ECUT must postulate some reactions that are long-shot possibilities, that no one is studying, and 
that might be workable. Some very inefficient industrial processes must be identified where an improvement would make good economic sense. Candidate research areas should be long-term and high-payoff in nature. The research could lead in directions that normally would not be pursued.

Collaborative research between ECUT and industry is essential for the success of CBD. However, establishing such a working relationship is difficult. Company $B$ felt that only when a catalyst is a proven winner and the company has a market segment "sewed up" will it be willing to use a university or a DOE laboratory for research. In their opinion, if a CBD user facility was set up at a university or national laboratory, the leaders in the field would not join. They will have too much to lose by sharing their proprietary data and feel that they do not have much to gain. However, those that are not in the lead would welcome a user facility. Thus, such a facility may be beneficial, since it may foster increased competition.

Company $B$ believes that the best method of encouraging technology transfer is to bring industry people into the universities and DOE laboratories to work on methodologies rather than proprietary research. They could lead the universities in the right direction without revealing exactly why. Personnel exchange in the reverse direction will also be beneficial. However, that normally happens as graduate students and postdoctoral fellows frequently seek and obtain employment in industry.

In addition to the acrylonitrile catalyst development efforts, other "creative" catalyst R\&D was always ongoing at Company $B$. This creative part was a much larger share of Company B's catalyst R\&D. The secret is to "run with the winners and cut your losses quickly." Catalyst research, Company B feels, is like the venture capital business - one major success out of 20 attempts is adequate to provide handsome returns.

The steps Company B envisioned in market-driven catalyst development activities included:

1. Evaluate catalyst performance in a l-gram micro-reactor.

2. Then evaluate it in a 2.5 -inch fluid-bed reactor. 
3. Then evaluate it in an 18-inch reactor, which one can correlate with the plant.

4. Company B generaliy took one reactor out of service in the commercial plant and loaded the new catalyst.

Market assessment and cost analysis is clearly the first step. Basic research is usually ongoing on the side.

Company B suggested the following sequence of catalyst R\&D steps. It begins with definition of the corporate goals, followed by identification of technology goals. At this point, fundamental research (to explain a known phenomenon) and exploratory research (to look for a new phenomenon) are ongoing simultaneously. When a catalyst invention is made, it moves into the "advancement" stage. This is the crucial economic decision point - should the catalyst move on to the pilot plant stage? At least $40 \%$ of the catalysts go from "advancement" to an actual pilot plant. After the pilot plant stage, the catalyst goes into commercial testing and technical service phases.

\subsubsection{Company $C$}

Company $C$ discussed a recent proposal submitted by a consortium of government, university, industry, and military participants for a NASA space center to be located in Cleveland. Their recommended model for how the space center would function may be applicable to a potential CBD user facility. There would be a large core group of scientists at universities with a scientific research program sponsored by state and federal government and private industry funds. These scientists would have a high degree of freedom to publish their research results. At the same time, there would be proprietary industrial subprograms ongoing in which the scientists would not disclose any proprietary information.

When asked to define the advantage of CBD, Company $C$ responded that CBD will improve the quality of catalyst screening activities, but may not reduce the number of screenings. They believe that the CBD vision is correct, but it will require a sustained long-term effort because there is a serious lack of understanding of catalytic mechanisms. Thus, they felt that the CBD objectives are desirable, but very difficult to achieve. 
One key point that Company $C$ made was that tremendaus improvements are possible in the field of biocatalysis, given that researchers in this field are very low on the learning curve right now. Unfortunately, adequate scientific training at the university level is not yet available. However, chemical engineering departments are beginning to develop courses on biocatalysis process design.

Company $\mathrm{C}$ is involved in the Tubrication industry and is a user of biocatalysts. They stated that the high-pressure fat splitter that is currently used in the fats and oils industry could become obsolete due to potential advances in biocatalysis.

Biocatalysis will probably not have an impact on high-volume bulk chemicals in Company $C^{\prime}$ s view. Thus, large energy savings will not be possible in this area. However, chemical treatment costs can probably be limited to only 1-2 cents per pound with biocatalysis.

When asked to describe the impacts of CBD on U.S. industry, Company $C$ answered that nothing should be expected for 10-20 years. By then, the CBD Program should have developed a series of techniques to aid industry in doing its business. They said that it is impossible to quantify the benefits of $\mathrm{CBD}$, but nonetheless they feel that it ought to be vigorously pursued. It is their opinion that science such as this has not been nurtured at U.S. universities.

CBD needs a mission comparable to that of the space program, as well as a key focused program. It needs a long-term focus, and must be funded to completion. Possible areas to focus on are those that would require researchers to break new ground in catalysis. Two examples are coal gasification and the production of liquid fuels from methane.

In closing, Company $C$ cautioned that we should not study the process, but just the science. No large demonstrations should be funded by the government; industry will do those.

\section{1 .4 Company 0}

Company $D$ stated that predictive chemistry in any field will be more than welcome. They said that, obviously, it would be great if CBD could be done; 
but of course, it will not happen for a long time. They believe that people who have been successful in catalysis have always used a CBD-type approach in which a model is used and feedback is provided to it based on the experimental results. Catalyst researchers typically insist on developing a hypothesis as a predictive base for the ongoing catalysis research efforts. For example, one scientist at Company $D$ cited the fact that of the 142 patents issued to him, only two came "out of the blue." The rest, he believes, were due to the approach described above. Thus he believes that what CBD is trying to accomplish was indeed being pursued by his research group, even though no formal theoretical effort was undertaken by them.

In Company $D^{\prime} s$ opinion, researchers will probably have success with the CBD approach in biocatalysis before they do in chemical (heterogenous) cata. lysis, since biocatalyzed reactions are relatively simple to understand. Biocatalysts usually have a single catalytic site that does not have many strong interactions with adjacent sites. The ability to model such single sites is simpler than modeling large clusters of metallic catalysts on complicated supports where catalyst-substrate interactions play a major role. The research programs of Peter Schultz (U.C. Berkeley) on biocatalysis and Adam Heller (AT\&T Bell Labs) on enzymatic electron-transfer reactions were considered by Company $D$ to be pioneering efforts and should be considered as part of a CBD Program in biocatalysis.

When asked where the savings would occur with CBD, Company $D$ said that it would make it easier to "do the last experiment first." That would lead to major savings. However, we must keep in mind that the research phase is still relatively inexpensive compared to pilot-scale work, at least in the petroleum refining, petrochemicals, and chemicals industries. Thus, industry is pursuing modeling approaches to pilot-plant testing and commercial reactor design very aggressively.

American business is generally too conservative to undertake high-risk projects such as the development of a totally new catalyst via a brand new reaction. However, even when they do, the rule of thumb is that the new catalyst and the associated process must offer a $30 \%$ cost advantage over the 
existing process, which is very difficult to achieve, especially when one considers the high cost of capital. It is one of the reasons why catalyst research has not received greater attention.

In the petroleum refining, petrochemicals, and industrial chemicals industries, the cost of the research phase of catalyst development is minuscule compared to the development and commercial-scale testing of new catalysts. Thus, even if significant savings in the screening effort can be achieved through $C B D$, its overall impact may not be significant. However, in these areas, theoretical modeling that may reduce pilot plant operation time or make the pilot plant design and construction more efficient will be of tremendous value in reducing costs and improving the efficiency of the catalyst development process. Thus, theoretical simulation of pilot plant operation, which is strongly supported by industry, is already very sophisticated.

In pharmaceuticals, on the other hand, the research phase is an enormous expense (30-40\% of the budget compared to less than $2 \%$ in petroleum refining) because the scale is so much smaller. In biotechnology and pharmaceuticals, the largest savings will be in the research phase. In petroleum refining, the savings would come from predictive models for large-scale plants.

In addition to these advantages, Company $D$ pointed out that the Europeans and the Japanese are becoming very strong in catalyst research and are taking a much longer-term perspective than American companies are. Company $D$ believes that they will develop CBD, and so we must also develop it just to stay competitive.

To a large extent, industrial catalyst development data are proprietary; this is a very serious situation that cannot be changed. Industrial participants cannot classify catalysts and cannot give out catalyst samples. However, we should continue to push for interactions between industry, academia, and government. The Japanese and the Dutch have strong networks to gather scientific information from all sources. The United States must wake up and do this, too. 


\section{1 .5 Company $E$}

In Company E's opinion, the CBD goals are moving targets, and are quite long-term in nature. It was felt that ECUT would need to develop an interdisciplinary approach, including solid-state physics, to understand the semiinfinite or repeating characteristics of the grains (voids or steps).

CBD will provide some mechanistic understanding, at least, of the relationship between structural and chemical properties. Selectivity witl be improved by CBD suggestions. Understanding cluster-size effects and amorphous porous structures will be improved. The downside to CBD is that one can get immersed in a particular model and not look at the problem from other perspectives.

Proprietary catalyst knowledge bases already exist in industry, al though in many cases the catalyst developers do not know why the catalysts work the way they do. Company $E$ believes that understanding is a luxury, not a necessity. If a catalyst works, one can afford the luxury of finding out why it works. They also pointed out that any totally new catalyst discoveries will probably be serendipity, not predicted events.

Company $E$ would like to be able to design a catalyst in the lab and guarantee that it will meet emissions requirements in the field $100 \%$ of the time. They do not have a good way to design for the "tail" (the last 1-5\%), so they consistently overdesign the catalysts. Maybe they could save $10-20 \%$ of the noble metal requirements if they did not have to overdesign. This could result in savings of tens of millions of dollars for Company $E$ alone, and hundreds of millions of dollars for all automobile producers.

They recognize the computer as a valuable tool in molecular design, but they cannot quantify its impacts yet, since such efforts are relatively new. They pointed out that the computer can lead to experiments that one might not have done otherwise. However, the present generation of computer models is not predictive; they are just increasing our understanding. It was the general consensus that predictive models are a long way off in the future.

Company $E$ is looking at bonding problems and surface interactions in catalysis, batteries, and fuel cells. Reasons for doing this research include 
1) they want materials with new properties, or 2) they want to understand what they have now, or 3 ) they want materials that do the same thing, but at a Tower cost. Using Biograph-type software, Company $E$ intends to optimize the membrane of a proton exchange membrane (PEM) fuel cell and generate predictions of novel catalysts for electrochemical methanol oxidation.

In reference to the secretive nature of catalysis R\&D programs, Company $E$ said that when people are keeping their work secret, they are not doing basic research, and there is probably not much understanding. They are just "tweaking the parameters" to come up with something that they can sell.

The CBD Program should adopt the structure for industry/government interaction that is used in the ECUT Combustion Program. Company $E$ is a member of several of the combustion working groups. They hold meetings twice a year, and Company $E$ feels that these meetings are quite impressive. The working group members have developed internal techniques to share information comfortably. The research to understand the fundamental issues is done at Sandia National Laboratories (SNL) and at universities. Company $E$ believes it improves the efficiency of their own R\&D by leveraging the basic research ongoing at the national laboratory with the advanced equipment and facilities that they already have. It would cost company $E$ more to do the experiments themselves.

Company $E$ is interested in direct methanol oxidation, and they are looking at the liquid/solid interface. They had no doubt but that they should use computer simulation techniques to assist them in catalyst screening, so they went to see Bill Goddard at Caltech. They created a research grant for him to understand ionic motion in polymer electrolytes. They are interested in determining whether the $C B D$ art has developed to such a point that it can be useful to them.

\subsubsection{Company $F$}

The person we interviewed in Company $F$ was emphatic in his statement that catalyst design is not totally empirical now and that it is erroneous to assume that computer modeling is a panacea that will alleviate this problem totaliy. In his opinion, one has to be careful in defining what one expects 
to get from a modeling approach since most comnercial catalyst systems are rather complex, and modeling from first principles may not be practical.

We heard a fascinating case study of a "technology-driven" catalyst development effort: "Dr. A" personally was interested in exploring a secondgeneration catalyst for reforming and wanted to explore bimetallic catalysts for this application. The well-known Gurney-Mott theory at that time discussed the role of "electronic" factors in catalysts, and the general consensus was that bimetallic alloys allowed one to vary this electronic factor and determine its effect. The results, however, were mixed, since the alloy composition and, consequently, the electronic properties of the alloy on the surface tended to be different from that in the bulk. Dr. A approached his research on bimetaliic catalysts with two somewhat different objectives:

1. To explore whether these alloy systems produced any change in selectivity.

2. To develop a practical catalyst system, i.e., a highiy dispersed, high-surface-area system.

In terms of selectivity, he hit upon a "gold mine." Different reactions were affected very differently. The rates often changed by orders of magnitude. In his attempt to produce a highly dispersed alloy, he impregnated salts of the metals he wanted to alloy on alumina and then heated them in a reducing atmosphere. This is the same technique that was used to produce highly dispersed platinum on alumina. One of the early systems he investigated was ruthenium/copper. With this catalyst system, he found a threeorders-of-magnitude decrease in the rate of the hydrogenolysis of ethane to produce methane compared to ruthenium only. There was no question that copper was having an effect. However, from the phase diagrams, copper was not supposed to form an alloy with ruthenium.

Painstaking research for several years finally proved that a new phase was being formed between ruthenium and copper in these highly dispersed systems. The term "bimetallic clusters" was coined to describe these phases. They are still not completely characterized, and a large volume of research is under way to better define these systems. One such bimetallic phase of platinum and iridium turned out to be an excellent catalyst for the reforming 
reaction. With a coworker, Dr. A started tests of this catalyst with naphtha feedstocks in 1967, and it is remarkable that the catalyst was commercialized by 1971 , only 4 years after the first testing began.

Several conclusions can be drawn from this short case study:

1. Discovery of a catalyst comes first, usually after a researcher undertakes the search for a new catalyst based on his/her own convictions and a rather vague hypothesis to be tested.

2. Good science follows the discovery and helps one to understand the principles involved in the discovery and to optimize the catalyst properties.

3. A large research program is not a prerequisite for a breakthrough; good ideas and tenacity are.

4. Fast commercialization of a catalyst system is possible if the conditions are right. Below we will examine the factors that led to the rapid commercialization of the platinum/iridium reforming catalyst by Company $F$.

5. The primary impacts of CBD will be in developing good science and contributing towards catalyst design and optimization for practical applications.

The rapid commercialization of this catalyst was very much marketdriven. In the late 1960s and early 1970s, there was a strong drive to remove lead from gasoline. To maintain a high octane rating, however, the oil companies needed more aromatics in the gasoline. The Pt/Ir catalyst allowed that to happen better than the Pt-on-a]umina system. In addition, this was the period of time when a tremendous growth in reformer capacity was occurring. Finally, this catalyst could be employed with only minor changes in the design of existing reformers. It is, thus, important in selecting projects for CBD to keep in mind that not only should the project, if successful, have a large industrial impact, but also the market forces must be right for its commercialization.

A second case study we covered involved collaborative research between two industrial laboratories. In the early 1960s, "Dr. B" was one of the pioneers in $x$-ray absorption spectroscopy [extended $x$-ray absorption fine structure (EXAFS)]. Having met Dr. B in a chance encounter, Dr. A was convinced that EXAFS would be a valuable tool in characterizing the bimetallic 
clusters and wished to undertake a collaborative research program with Dr. B. Although Dr. B's research laboratory was not involved in any type of catalyst research, there was considerable opposition within Company $F$ for such collaboration. Dr. A prevajled, but it took some time, the research agreement was strictly limited to using the EXAFS technique, and there were severe restrictions on the sharing of reforming process data. Having achieved this collaboration, he was successful in convincing Company $F$ to set up a similar agreement with Stanford for the use of their synchrotron facility to continue his EXAFS study. This collaboration started in 1975 and continues to the present. Success in this collaborative research has now prompted other Company $F$ researchers to use the Brookhaven synchrotron facility.

The primary impression that $\mathrm{Dr}$. A conveyed to us was that collaboration between any two entities will require champions on both sides willing to face and overcome the initial opposition and remain committed to the collaborative effort. Once initiated, these types of collaborative efforts tend to work out we11. In terms of $C B D$, therefore, we need to not only identify key companies, but also individuals in the companies who will champion a collaborative research effort.

The U.S. catalyst industry is very competitive in the internationa? marketplace. However, in Dr. A's opinion, this very success has generated an attitude that we can rest on our laurels and still maintain our competitive position. As a result, there have been significant lay-offs in the research staff in this industry over the last few years, including some at company $F$. Dr. A strongly felt that this shortsighted approach will have a deleterious effect on the competitive position of the industry in the next five to ten years. He feels that a government program such as CBD can give a boost to industry and encourage them to undertake more research. It will also help in producing we11-trained catalyst researchers who will be available when industry realizes their mistake and starts reinvigorating their catalyst research efforts. 


\subsubsection{Company $\mathrm{G}$}

Company $G$ develops and applies molecular mechanics and dynamics methods to solving problems in the areas of polymers, materials, metal clusters, surfaces, and large molecules. Local density function theory is the bas is of their approach. Using this approach, Company $G$ tools can map surfaces using potential energy functions (PEFs). PEFs are a series of terms built up from theory and fitted empirically to a surface known from crystallographic data. Company $G$ is adamant that their approach is better than other ab-initio techniques because of the reduced computational requirements.

Application of local density function theory has been limited in the past by the small amount of experimental data available for parameterizing the potential energy function. There were also a number of serious concerns about the appropriate form for the potential energy function. In order to solve these problems, Company $G$ formed a consortium to derive and validate accurate "second-generation" potential energy surfaces for organic, pharmacological, and other biomolecules. Several software programs were developed. Databases of both experimental and ab-initio properties were also initiated. Use of these tools is available to consortium members.

Company $G$ has been very successful at drawing together companies to develop predictive tools. Twenty-four companies who support their potential energy function consortium told Company $G$ to look at polymers and develop modeling tools. They are now about to launch a project in the catalyst area, which will initially focus on zeolite systems, with the expectation that problems associated with zeolite catalysis can be studied using local density function tools.

In the exploratory phase, the pharmaceutical industry might conceptualize 20,000 compounds and spend about $\$ 3500$ each to evaluate them. In the labora-

tory phase, they might test about 20 compounds at a cost of about $\$ 3.5 \mathrm{million}$ each, then one or two products might reach the clinical testing stage at a cost of about $\$ 70$ million.

CBD tools might allow companies to evaluate highly speculative concepts. In addition, researchers could evaluate concepts in conditions totaliy 
inaccessible to experiment. These tools would also allow more sensible testing during the laboratory and bench-scale phases. The research team would only need to evaluate the novel aspect of product or process performance.

A modeling team might cost a company $\$ 3$ million to maintain. Even if such a team improved the efficiency of catalyst development by a small percentage, the benefits would more than offset the costs.

It is important that methodologies be developed so they logically flow into the commercial sector. One problem with academic codes is that they are sloppily written, so they do not achieve broad use in industry. The contractor chosen to do research must be knowledgeable of industrial catalyst development methodologies and understand their informational needs, and in what form the information should be structured and presented so that it will be used and accepted. Government might want to participate in such events as the biannual meeting of the International Zeolite Society. Technical issues and information of any nature relating to zeolites as both adsorbents and catalysts are presented at this meeting.

Company $G$ believes that CBD technology is in its infancy. An important government role would be to help develop and refine quantum-level models of catalytic systems. Many methods being developed today depend on empirical parameters, but there is not much data in the literature from which such parameters can be drawn. Work needs to be done to quantum mechanically or experimentally derive these parameters so that algorithms can be developed to predict the behavior of real systems; then these algorithms must be verified by comparing theoretically derived results to real-life systems. Zeolites, of course, are a class of catalysts with many large-scale applications in the chemicals and petroleum industries. In the field of zeolites, there is an enormous amount of information available, but most is experimental.

There is fairly good economic incentive to develop software once some fundamental methodologies are established. There is no lack of new concepts for theoretical catalyst design, but supporting the evolution of new concepts into practical tools that can be used by industry is an important area. For example, extending a theory developed for a one- or two-component system to a three-component system would be a very expensive project that industry might 
not want to tackle. The logical extension of concepts to predictive algorithms that can realistically be applied to industrial systems might be a legitimate role for Government. The partnership would be between companies such as Company $G$ and academia or national laboratories.

A good area for government is to solve CBD problems in milestone areas of research important to energy conversion; methanol to gasoline is an example of such an area. We need a better understanding of the reaction pathway, and we need to understand the molecular-level chemistry in order to develop predictive molecular design tools. A better understanding of the active sites and algorithms to predict what is going on catalyticaliy would have a lot of benefits for industry.

\section{1 .8 Company $\mathrm{H}$}

Company $\mathrm{H}$ is very interested in being involved in an ECUT effort for developing a more predictive base for catalyst research. A reason is that their own research program is based on computer-assisted catalyst design.

Biocatalysis, in particular, is an important interest of Company $\mathrm{H}$. Their company started its initial R\&D emphasis in 1982 with the idea to use biological systems as models for chemical processes. By 1989 they had expanded their portfolio to develop their own technologies in areas of catalysis (not just biological) that make strategic business sense. They have a service called Advanced Catalyst Technologies (ACT) that does six studies a year and conducts a workshop to help focus technical ideas; most of their R\&D emphasis is in response to a market-driven need, which may be a previously discovered novel catalytic process with good market potential. They do not have a basic research laboratory so they do not discover catalysts.

Timing is a function of the complexity of the problem as well as the resources and knowledge available. An easy problem may require as little as 2-3 weeks to assemble a team and a few months of laboratory work. If a commercial plant already exists, the product can enter the marketplace in a very short time. For example, Monsanto's acetic acid technology took 4-5 years to develop. If the idea is a new concept such as methane to liquids, it can take 10-15 years to reach a product development stage. If the project has an 
extraordinary leader, such as the ICI syngas process, a new technology can be developed in as little as 3 years.

One needs to be very conservative about defining CBD; Company $\mathrm{H}$ prefers to use the words "computer-assisted design." CBD will help scientists pick the winners, and most importantly, to decide what materials not to test. They do not agree that a company should spend a set time on exploratory research, but this may be the culture of large companies. It may be a culture that is hard to change, but CBD could definitely allow companies to cut the time frame for exploratory research.

A second area of impact is based on the fact that research conducted early on guides research in the later phases of a project. A pilot plant can be defined as that phase of the project where the catalyst is tested in its final form under actual process conditions. A better understanding of cataTytic mechanisms such as deactivation methods (therma1, byproduct, or impurities) may mean that a simpler pilot plant (a plant that evaluates only the novel aspects of a catalyst's performance) can be constructed. If models that combine chemical reaction engineering with physical and chemical phenomena are developed, it may even be possible to use CBD to bypass the pjlot plant altogether. If an optimum or better quality catalyst is developed because of CBD, the commercial plant will be simpler too. The economic impact of better selectivity, higher yields, and lower process or feedstock energy consumption would be tremendous.

There are two aspects to cutting time in the catalyst development process: one is smart science (such as CBD), and the other is the need to include engineers, marketers, and legal people in the early stages of a process. Anything that helps a company recognize the technical issues before a plant is built will help ensure a successful plant.

Catalyst development is reaching the point where a catalyst may be discovered in Holland, developed in the United States, and manufactured someplace else. How CBD helps U.S. competitiveness will depend on how the knowledge is applied. Restricting access to information may not be in our best interest, 
but does not give the technology away either! Stanford University is also dealing with this. Foreigners coming for postdoctoral work essentially recejve a free education and then take the technology base with them.

The Japanese are becoming more and more interested in catalysis, but they may not be our only future competitors. Company $H$ is impressed by the work the Europeans are doing. A French researcher is applying molecular chemistry to catalytic problems with a half dozen theoretical people doing the work. Another French researcher is studying super molecular catalysis. He used a quantum-mechanical approach to study how reactants fit into catalyst pockets.

Company $\mathrm{H}$ specializes in the discovery, development, and commercialization of advanced catalytic products and processes through the tools of molecular engineering. Molecular engineering is at the stage where it is offering exciting new opportunities for designing specific catalysts to fit individual industrial needs. A few years ago, Company $H$ conducted a workshop on assisted catalyst design as a part of ACT. They have published an ACT study that assesses how organometallic chemistry, surface science, reaction engineering, chemical kinetics, and computational modeling can contribute to the design of powerful new catalysts.

Any collaborative effort, which will be very difficult, must protect the proprietary rights of industrial participants. An historical example of such a collaborative effort is the National Institute of Catalys is (in the 1950s), and presently regional centers such as Northwestern University, the University of Delaware, and Berkeley, which are supported by local industry. It should be noted that providing a forum for communication may be the best way to establish a collaborative program.

ECUT may want to have a center specializing in applying computation to catalyst design; a smaller, less visible organization would be more desirable because a big institute is not very productive per dollar. High-quality people should be involved, and the effort should have well-defined goals and objectives and measures for meeting these objectives. Company $H$ has reservations about a program that focuses on a specific type of materials. 
Company $H$ would $1 i k e$ to see the government get involved in helping industry do their job better because industry will not spend the time to develop a quantum-mechanical basis for catalyst development. Molecular graphics is not that well developed in the area of catalysis either.

What scientists really need from the computer is guidance, and not the whole answer. Since computers are a long way from totally representing a system, they can never replace serendipity. Serendipity results from undiscovered phenomena, but computers can stimulate thought processes that lead in new directions that might otherwise be lost.

R\&D funding in this area is based on the expectation that biocatalysis will provide a means for more efficient chemical transformations of both known and alternative feedstocks. Many interesting possibilities have been suggested, including such ventures as the propylene-to-propylene oxide process studied at Cetus Corporation. However, practicality limits the application of this technology to large-scale chemicals production. Enzymes may be costly, unstable to use, have low intrinsic activity, and have low catalytic activity by weight.

\section{1 .9 Company I}

According to Company I, the CBD approach will allow companies to develop better products. Simulation gives researchers time to get a clearer picture of the product they are trying to develop and to understand its physical and chemical properties. Thus the product, once developed, is much more likely to work. It may allow a company to develop products faster and cheaper because a lot of wasted experimental effort is eliminated. However, this is not the current emphasis of Company I's users.

No companies have come to Company I concerning problems encountered while applying Company I's tool for designing catalysts, or with suggestions for developing a better tool, which makes one think they are doing very little in this area. A reason may be that they are having difficulty getting experimentalists to use simulation tools. Company I tried making the product more user-friendly, but this had little impact. Applying simulation to catalyst 
research is especially difficult because transition metal interactions are poorly understood. Protein modeling is much easier.

It is not difficult to convince industry to form an exploratory group to see if this approach has any application to the work they do. The problem is that these groups tend to become highly specialized and enamored with keeping up with the latest in simulation and modeling technology. They become so intent on keeping up with the latest that they lose sight of their original purpose; they become more and more specialized and less and less aware of their companies' needs. Other groups can access this expertise, but because of the high degree of specialization and complexity, this expertise cannot easily be transferred to other groups. They tend to become overwhelmed with requests for services, but unable to solve their problems in a cost-effective manner. Eventually they evolve into groups working in isolation with the rest of the laboratory on only one or two specific projects. An advanced center could be set up at the laboratory where CBD tools are made available to the users. Training would be available so that industry would understand what these tools are capable of doing.

Industry needs to participate in focus groups. They need to talk about what they are trying to do with these simulation tools, as well as what they need to broaden the applications or to improve the use of CBD tools. Currently there is such a lack of communication that companies such as Company I have difficulty understanding what products are needed. Industry needs to get together to think about this issue and provide the specifications for what CBD products should look like. In addition, the specialized exploratory groups should make more of an attempt to transfer their knowledge and skill to other groups. The tools are still primarily in the hands of the theoreticians, and scientists need to be able to use simulation tools on their own.

\subsection{WORKSHOP PROCEEDINGS}

The first CBD workshop, held on July 20, 1989 at the California Institute of Technology (CALTECH), focused on R\&D issues related to biocatalysis. The second CBD workshop was held on August 30, 1989 at the Argonne National 
Laboratory (ANL) and dealt with R\&D issues related to chemical catalysis. (The third workshop is discussed in Chapter 6.0). The objectives of the two workshops were:

- to inform participants about ECUT's role and mission and to explore how industry, the national laboratories, and academia might participate in the CBD Program

- to assess the potential impacts of the CBD effort on the U.S. chemicals/petrochemicals industries; in particular to discuss how such a proposed program could assist U.S. industry in maintaining its competitive position in the global marketplace

- to develop and prioritize a research agenda for CBD that will be beneficial to the U.S. chemicals and petrochemicals industries.

Summaries of the proceedings of the workshops are presented in the following sections. For more details, see Proceedings of the Catalysis-byDesign Workshops (Fassbender et al. 1990).

\subsubsection{Biocatalysis Workshop}

The agenda for the biocatalysis workshop included both formal presentations and informal discussions. The morning session focused on the role and mission of ECUT, especially as it pertains to the CBD Program. The afternoon session concentrated on developing a research agenda for applying CBD techniques to biocatalysis.

The biocatalysis workshop was not well attended by industry; in fact, there was only one industry representative present, although about a dozen companies were invited to participate and several indicated that they would attend. There were twenty-three participants in all, mostly from the national Taboratories. The workshop was moderated by Dr. William Goddard, of Caltech, who has been involved in the ECUT Biocatalysis Program for several years.

The ECUT Biocatalysis Program is an applied research and exploratory development effort focused on providing the enabling technology base for new industrial bioprocess applications. The primary objective is to resolve critical bioprocess engineering problems that impede the economically 
competitive biocatalyzed production of high-volume, energy-intensive chemicals where genetically modified and/or engineered microorganisms or derived enzymes are used.

Catalysis-by-Design was an area recommended by the ECUT Biocatalysis Program Guidance and Evaluation Panel as a new project thrust. CBD is defined by ECUT as the in-tandem use of instrumentation, theory, and computation, focused on generic problems in catalysis, to develop experimentally validated models of catalyst performance. Since a substantial part of the ECUT Biocatalysis Program is directed at enzyme reactions, enzyme stability, and metabolic engineering to make better use of enzymes, an in-depth research program could be implemented. This would combine existing data and molecular modeling techniques to predict structures which would give more stable enzymes or change enzyme specificity, which could lead to significant progress in advancing the industrial applications of bioprocess engineering.

A logical extension of this type of biocatalysis research would be to use knowledge of chemistry and molecular modeling techniques to predict structures of inorganic catalysts for chemical processing. If such an approach were successful, it could reduce or possibly even eliminate the extensive screening processes that are currently used by industry to identify and optimize catalysts for chemical production.

\section{CBD Research Agenda}

Dr. Goddard began his presentation with some issues to consider when selecting technical areas for the CBD research agenda including:

1. What is the time scale for technology transfer?

2. What are the costs involved in terms of people, hardware, and software?

3. What is the payoff? How big? How soon?

Some key questions to be addressed include:

1. Is the theory actualiy any good?

2. Can we predict structures?

3. Can we trust the predictions? 
4. How well do we describe the various interactions?

CBD should allow a researcher to conceive of a system and check out his/ her predictions in a reasonable amount of time. The ability to iterate between prediction and observation is what makes this "design." A secondary question is "If you design it, can you actually make it?" That is, the design strategy must make sense synthetically. Theory does not have to give you "the right answer," but it needs to identify "the wrong answers."

The following subsections provide summaries of the workshop discussions related to theory, modeling, instrumentation, key systems to study, critical issues in CBD, development needs, and the need for a user facility. In many cases, no consensus was reached regarding exactly what should be done, but the summaries contain important background information that will be useful to ECUT in developing the CBD Program.

\section{Theory}

The objective is to design new artificial catalysts, not biological catalysts. However, the most efficient way may be to study natural catalysts (enzymes) to learn the rules, and then to use the rules to design artificial systems. Learning from nature will enable scientists to transiate the natural system into a system with desirable characteristics (e.g., greater stability at higher temperatures). That is, scientists will be able to modify biological systems into artificial systems that meet their needs. As an example of this, it was mentioned that it would be desirable to develop non-aqueous enzymes to eliminate separation problems. In other words, the goal is to mimic natural systems but have the freedom to change the operating conditions. If it is possible to understand what nature does in terms of catalysis, then perhaps it is possible to simulate it with chemical catalysis for bulk chemicals production. Hopefully, polymer synthesis also will one day lead to the desired selectivity and control.

The first step is to determine the requirements for designing a catalyst. For example, what must be known about an active site? One participant said that specificity, stability, solubility, folding, and conformational changes 
that occur on binding must be understood. Another participant mentioned that what must be understood is encompassed by structure/function/energy relationships.

\section{Modeling}

Someone asked if there is a market for these tools. Or. Goddard replied that industry needs answers; they do not have time to develop tools. Unfortunately, people in industry are driven by what they think they can realistically accomplish, not what tools they might like to have.

A participant asked "Can you create systematic tools that will allow creative organic chemists to go beyond their intuition?" Dr. Goddard responded that it is possible, but no one really knows how close this is to being a reality.

The general consensus of the participants was that ECUT should emphasize tool development rather than solving specific technical problems. These tools must be useful for solving many important problems, not just one specific problem. Industry will take the tools and tailor them to the specific reactions that they feel will be commercially useful.

It was pointed out several times that any tools developed by ECUT must be "confronted" by experiment. In fact, it was stated that CBD can "catalyze" the interactions between theorists and experimentalists so the process goes a little faster! The applications used to verify the tools may not be biocatalytic systems at a11, but may be organic systems instead.

Tool development should be done with an emphasis on time-resolved studies. Simulation and prediction of spectra should be combined with experimental measurement, followed by calibration and verification of the tools for systems relevant to biocatalytic systems. Tools must be usable by nonexperts (i.e., those not involved in the tool development). The ultimate end product is a tool that combines theory and experimental results that industry can use to develop biocatalysts.

It was felt that ECUT should build a model to characterize the thermodynamic properties of known enzymes, then that information should be used to determine data needed for other systems (e.g., solvation energies, substrate 
binding energies, energetics of the active sites). The initial focus should be on characterizing known enzymes, and then extrapolating that knowledge to use it as a basis to study unknown systems (structure/function/energy relationships).

\section{Instrumentation}

Several participants agreed that industry wants to understand active sites, and they want instrumentation to analyze what they are doing. It was felt that ECUT should develop instrumentation and analytical techniques such as spectroscopy and nuclear magnetic resonance (MMR). It was also stated that a theoretical understanding of time-resolved spectroscopy is needed.

\section{Key Systems to Study}

The following types of reactions were considered the most important areas to study:

- methane oxidation (or oxidation of hydrocarbons in general)

- nitrogen fixation

- photosynthesis

- $\mathrm{CO}_{2}$ fixation

- water splitting

- desulfurization

- dehydrogenation

One participant said that a decision is needed regarding what products would be likely targets and what energy savings would result. Another countered that it would be best to focus on generic mechanisms rather than specific end products since the economics and the markets are subject to change. Several participants felt that it is more important to study what determines stability, specificity, and affinity than to study specific products. 
It was proposed that the protein backbone be ignored because of its complexity, and the focus should instead be on the active sites. A polymer could be used as the backbone structure and still allow researchers to study the binding sites.

It was stated that the four steps that kinetically define cataiysis are 1) alteration of the site to allow it to catalyze the reaction, 2) diffusion and attachment, 3) making and breaking of bonds, and 4) release of the product.

The group should focus on the problems that must be solved rather than specific solutions. The three key areas to study are solvation, active site specificity, and electron transport, all of which interact and provide feedback.

\section{Critical Issues in CBD}

1. What are the geometric and electronic properties that characterize an active site?

2. What kinds of essential structural characteristics occur in inorganic enzymes that are catalytically interesting?

3. What makes enzymes thermostable?

4. How can the knowledge of mechanisms (sequences of chemical steps that lead from reactants to products) be harnessed to design catalysts?

5. How can we control and modulate stearic effects in enzymes?

6. To what extent can the protein be stripped away and replaced with a polymer while retaining the activity?

7. How can biocatatytic processes be made useful on an industrial scale?

8. How can methods be developed to redesign a catalytic site, to predict how that redesign will act in catalysis (i.e., what will its specificity be?), and to anaTyze what is made?

9. What is the relationship between medium-to-1ong-range structures and the active site mechanisms?

10. How do protein/solvent interactions, which lend themselves to modeling, promote or inhibit the desired reactions? 
11. Can a biocatalyst be altered or redesigned from an existing biocatalyst by manipulating the folding pathway? What new properties, if any, would exist?

12. Can a protein compete in cost with existing catalysts?

\section{Summary of Development Needs}

1. Modeling tools to predict structures or what would be a change in a given structure and function (e.g., catalytic activity, thermal stability, robustness, regulation).

2. Improved methods to actually make those alterations (the enzyme that was designed).

3. Analytical methods to characterize the products of those alterations, both in terms of structure and function.

4. Methods to adapt the system to industrial use (scale up to production levels), which would include scale up and also stability of the product.

\section{The Need for a User Facility}

A user facility could be developed for industry to come in and exercise the tools. For example, industry pays full cost recovery for experiments undertaken at Brookhaven's National Synchrotron Light Source, an existing DOE user facility. University students working in a user facility would go after graduation to the industries needing the tools; this constitutes effective technology transfer. The user facility would have state-of-the-art software and work stations, as well as the latest instrumentation capabilities (e.g., numerous types of spectroscopy).

\subsubsection{Chemical Catalysis Horkshop}

This workshop was well attended, with about thirty-five experts from industry, the national laboratories, and academia represented. The meeting was moderated by Dr. Alan Wilks from Allied Signal Corporation. Dr. Wilks has been involved with the ECUT CBD Program since its inception and led the original ECUT assessment to evaluate the feasibility of such a program.

The meeting agenda included two distinct segments. The morning session focused on the role and mission of ECUT, especially as it pertains to the CBD Program, and explored the potential impacts of the program on U.S. industry. 
The afternoon session concentrated on developing a research agenda for applying CBD techniques to chemical catalysis.

\section{Potential Impacts}

Catalyst research can be subdivided into two categories. The first is where an unanticipated discovery is made and technology moves rapidiy. The second is where steady incremental improvements in a catalyst system's performance are made after the initial discovery or in an already commercial catalyst system. Industrial research in this second category predominates. Indeed, there was a strong consensus at the workshop that theoretical models would not be sufficiently developed in the near future (within 5 years) to make any significant impact on the "discovery" of new catalysts. Most of the impact will come in the second category where incremental performance improvements are desired.

The primary impact of CBD will be to affect the heuristic "cut and try" catalyst screening process. A set of hierarchical models could allow one to simulate the catalytic behavior of novel materials and to eliminate undesirable candidates without having to operate expensive micro-reactors or pilot $\mathrm{plants.} \mathrm{The} \mathrm{efficiency} \mathrm{and} \mathrm{the} \mathrm{productivity} \mathrm{of} \mathrm{catalyst} \mathrm{R \& D} \mathrm{would} \mathrm{thereby}$ increase.

Two pertinent examples were cited to justify this claim. One was at DuPont, where thermodynamic calculations on a Cray supercomputer helped a research group to decide not to initiate a research project to develop a new catalyst for production of para-diaminobenzene. The cost savings to DuPont from avoiding the catalyst development project were estimated to be as much as $\$ 2$ miltion (Borman 1989). The other example was a Japanese research group exploring catalysts for conversion of syngas to ethylene glycol. Approximateiy 10,000 compounds had to be screened before an optimum homogeneous catalyst was identified. Imagine the time and cost savings that could be achieved if hierarchical models were available to explore the catalytic activity of the most likely of the 10,000 compounds on a computer instead of painstakingly evaluating their potential in the laboratory! 
Another benefit of the CBD approach is that once a discovery is made, an optimum catalyst can be developed more readily. Currently, the only way to measure a catalyst's performance is to compare the new catalyst to an existing one at the same process conditions. Opportunities to optimize catalyst performance may be missed because there is not enough time to investigate how a new catalyst might perform at other process conditions. Computer simulations of catalyst behavior at a variety of operating conditions will enhance the catalyst R\&D process and result in more nearly optimal catalysts.

There was a general consensus that the CBD Program is desirable and could have a positive impact on U.S. catalyst research efforts. According to one industrial participant, industry does not like to fund the development of tools, so tools must often be "bootlegged." A government/industry collaborative effort in CBD would give industry the opportunity to be more involved in tool development. In addition, the program would provide a forum for theorists to identify problems that need to be solved. Experimentalists would be exposed to new theoretical methods that can be applied to guide experimentation.

However, for the CBD effort to be successful, its long-term nature must be recognized and both industry and government must be willing to support it for at least a decade. A critical mass of resources, including personnel and instrumentation, is also required. A very preliminary cost estimate of such a program was approximately $\$ 10$ million annually over a 10 -year period.

Industrial participation and cost sharing over the same time period was also deemed essential for the success of the program.

\section{CBD Research Agenda}

The first item discussed was whether the CBD Program should identify one problem in catalysis research and focus its resources to attempt to solve that one problem. Much discussion centered around this issue. A particular problem suggested was methane activation and/or $C_{1}$ chemistry in general. However, as the discussion progressed, it became apparent that such an effort did not fit well with ECUT's mission. The objective of this program from ECUT's standpoint is not to develop a particular catalyst for a specific reaction, 
but to develop a set of generic modeling tools based on experimental verification that would be useful to the catalyst industry across the board. The discussion then centered around generic catalyst research areas that are of interest to both industry and academia.

The workshop participants suggested a number of research topics for the CBD Program to address, then each participant was given three votes to select what he/she considered to be the most important topics. While ECUT ultimately reserves the right to choose the research projects, the prioritized research agenda will provide valuable guidance for ECUT as it makes its programmatic decisions. 



\subsection{MECHANISMS FOR GOVERNMENT/INDUSTRY COLLABORATION}

This chapter is based mainly on the discussions that occurred at the CBD workshop on government/industry collaboration on September 28, 1989 in Washington, D.C.

\subsection{BACKGROUND}

Government/industry collaborative research received an inordinate amount of attention in the 1980s. The perceived decline in the competitiveness of U.S. companies and the need to increase productivity through new and improved technologies was well recognized by the workshop participants. A consensus emerged that spending government research dollars to develop private-sector technology is more effective when there is strong industrial participation, and collaborative research programs were seen as vehicles to accomplish this desired goal.

Many federal agencies supporting research have actively promoted collaborative research. These agencies include the National Science Foundation (NSF), the U.S. Department of Defense (DoD), the U.S. Department of Commerce (DOC), and the U.S. Department of Energy (DOE). The states have become involved and have sponsored many significant collaborative programs between industry and local academic institutions. The decrease in federal research dollars going to universities has prompted these organizations to approach industry to form collaborative research ventures. The ensuing proliferation of collaborative research can be seen in the approximately 19 collaborative programs in materials research initiated between 1983 and 1986. Most of these programs were academic consortia working with industry to conduct either basic or generic applied research.

Conceptually, there are many advantages to the collaborative research ventures, including:

1. The high cost of doing research precludes single companies from undertaking risky, long-term projects even if the potential payback is high. 
2. The collaboration allows each partner to leverage its investment in the research program.

3. Research programs often require a mu1tidisciplinary approach. A collaborative program facilitates assembling the required "critical mass" of researchers from various disciplines in a cost-effective manner.

4. Collaborations provide industry with new ideas and a pool of trained personnel from which it can recruit if required.

5. Intermediate- and long-term projects can be more easity handled through collaborative programs and can free up individual companies to support short-term product development activities.

Although it is still too early to assess the success of the collaborative programs, some trends are emerging. In an assessment conducted by OTA (Tornatzky et a1. 1987) where industrial, academic, and federal laboratory personnel involved in collaborative research were interviewed to assess the programs' efficacy, the results appear to be mixed. There is a consensus that collaborative research programs do contribute to increasing the technology base by conducting basic and generic applied research. In this sense they appear to be successful. However, the success appears to be marginal when evaluated against the objective of improving the competitiveness of U.S. industry. OrA repeatediy found only a minor impact in terms of industry using the collaborative research results for developing new products. Several factors such as the following may contribute to this finding:

1. The federal research laboratories are not able to undertake proprietary research.

2. The differences in organizational cultures are a contributing factor. For example, an academic or a federal researcher is more interested in research to advance knowledge as opposed to industrial interest in product development.

3. The lack of direct industrial participation in program planning and goal-setting results in complaints of the program being unfocused.

4. There is a lack of true technical exchange, including close contacts and exchange of personnel. 
5. Many U.S. industries exhibit lukewarm interest in governmentsupported research. This is indicated from the statistics that more foreign companies contact federal laboratories and express interest in collaborative research projects than do U.S. companies.

These conclusions are somewhat disturbing. The Federal Technology Transfer Act has addressed some of the structural problems and provided more incentives for federal research facilities to participate in such activities. This is definitely a step in the right direction. Coupled with the National Competitiveness Technology Transfer Act of 1989 that streamlines patent rights on government-supported projects, these incentives will undoubtedly improve the efficacy of collaborative research programs.

\subsection{THE ECUT APPROACH}

Although some of the structural problems are being addressed through legislation, there are examples of ongoing collaborative programs between industry and federal laboratories that are immensely successful, not only in developing technology but in transferring it to industry as well. The key success characteristic of such programs is to clearly focus on a particular problem area.

One such collaborative program is the Combustion Technology Program managed by Sandia National Laboratories that was supported by ECUT. This program, which was established in 1980, set the objective of performing generic applied research in combustion to develop enabling technologies for the industrial sector. It built on the tremendous foundation of basic research supported by DOE's Office of Energy Research (DOE/ER). Early on the program emphasized industrial collaboration in the technical details, as well as in establishing program priorities and goals. Several working groups, set up with strong industrial and academic participation to address specific technical objectives, directed the collaborative research efforts.

An interesting aspect of the Combustion Technology Program was that no funds changed hands. ECUT did not fund any of the industrial research and, conversely, industry did not contract for research by Sandia; both parties did their research with their own funds. The working groups were the forum for exchanging ideas and setting program priorities. 
The organization chart of this program, which identifies the working groups and the industrial and academic participants, is shown in Table 6.1. It is interesting to note that most major automotive companies and engine manufacturers have participated in this effort for a decade. It is also striking that there has been very little turnover among the industrial representatives; more or less the same research experts have participated in these groups since they began because the program has fostered the successfut exchange of

\section{TABLE 6.1. ECUT Combustion Technology Program}

Cooperative Working Groups

Engine

Combustion

\begin{tabular}{|c|c|c|c|}
\hline $\begin{array}{c}\text { Direct-Injection } \\
\text { Stratified-Charge } \\
\text { Group }\end{array}$ & $\begin{array}{c}\text { Dilute } \\
\text { Homogeneous- } \\
\text { Charge Group }\end{array}$ & Knock Group & Diesel Group \\
\hline $\begin{array}{l}\text { General Motors } \\
\text { Princeton University } \\
\text { Lawrence Livermore } \\
\text { Laboratory } \\
\text { Los Alamos } \\
\text { Sandia }\end{array}$ & $\begin{array}{l}\text { Ford Motors Co. } \\
\text { Chrysler } \\
\text { Imperial College } \\
\text { Massachusetts Institute } \\
\text { of Technology } \\
\text { Penn State University } \\
\text { UC Berkeley } \\
\text { Integral Technologies } \\
\text { Sandia }\end{array}$ & $\begin{array}{l}\text { Knock Group } \\
\text { Unocal (a) } \\
\text { General Motors }{ }^{\text {(a) }} \\
\text { Drexel University } \\
\text { Princeton University } \\
\text { Lawrence Livermore } \\
\text { Laboratory } \\
\text { Sandia }\end{array}$ & $\begin{array}{l}\text { Diesel Group } \\
\text { Cummings }^{(a)} \\
\text { Navistar }^{(a)} \\
\text { Exxon } \\
\text { Penn State University } \\
\text { Yale University } \\
\text { PSI Technology } \\
\text { Southwest Research } \\
\text { Institute } \\
\text { United Technologies } \\
\text { Los Alamos } \\
\text { Sandia }\end{array}$ \\
\hline
\end{tabular}

Continuous

Combustion

\begin{tabular}{c}
$\begin{array}{c}\text { Pulse Combustion } \\
\text { Group }\end{array}$ \\
\hline
\end{tabular}

Lennox Industries ${ }^{(a)}$

Forbes Engineering ${ }^{(a)}$ Gas Research Institute ${ }^{(a)}$ Georgia Tech University of Michigan Sandia

\begin{tabular}{c} 
Spray Combustion \\
Group \\
\hline
\end{tabular}

National institute of

Standards and Technology Jet Propulsion Laboratory Los Alamos

Sandia
Diesel Group

Cummings ${ }^{(a)}$

Navistar ${ }^{(a)}$

Yale University

PSI Technology

Southwest Research Institute

Los Alamos

(a) Corporately funded industry partner. 
technical personnel. Industrial representatives have spent time at the DOE facility to conduct research and transfer the technology to their parent companies.

It is important to note that this small collaborative research program has overcome all the organizational obstacles suggested in the OTA report. It is also important to emphasize that the keys to success have been: 1) the narrow focus of the program and 2) that it has been nurtured and sustained by both industry and DOE to allow establishing close working relationships between the researchers.

A computer code, KIVA, which is a tool for engine design and optimization, is one of the many results of this program. The KIVA code has been readily accepted by industry and is used today by virtually all engine manufacturers to better understand the combustion process and to improve the fuel economy of some current standard internal combustion engine designs.

ECUT intended to establish a similar collaborative research program in CBD because of two overwhelming reasons why such a collaborative program is necessary:

- Most catalyst research is done by industry, and they have developed a strong database of information that is relevant to the CBD Program. Such an extensive knowledge base is not available at the DOE laboratories or in academia. Consequently, the participation of catalyst manufacturers and users in the CBD Program is essential.

- ECUT's mission was not only to conduct generic applied research to develop a technology base for energy-efficient technology, but also to make a vigorous effort to ensure efficient transfer of the products to industry. To meet this mission, it is very desirable to solicit and obtain active industrial participation early in the program.

However, designing a collaborative research program with industry in the area of catalysis is not easy. The chemicals/petrochemicals industries are very secretive and consider their catalysis research activities to be highly proprietary. In addition, a catalyst developer often has detailed information on its clients' processes to assist in custom-making catalysts. Consequently, the developer will go overboard in maintaining its image as an extremely proprietary operation. In order to explore how a collaborative research program 
between such secretive industries and ECUT could be formed, ECUT organized a workshop in September 1989 with industrial R\&D decision-makers to discuss the issues involved and obtain a detailed industrial perspective of how such a venture should be organized.

\subsection{INDUSTRIAL PERSPECTIVE}

Traditionally, the federal government has avoided supporting catalyst R\&D except when it was judged to be necessary from a national security perspective. The healthy chemicals, petroleum refining, petrochemicals, and catalyst manufacturing industries justifiably carried the load in conducting research, development, and commercialization of new catalysts. The government role was to support fundamental research in surface science, fast reaction kinetics, and other areas to advance fundamental knowledge that may be of use to industrial catalyst researchers.

There is a growing realization, however, of a need to "span the gap" between basic research and applied industrial research through what is commonly referred to as generic applied research. This often is long-term in nature and beyond the capability of any one industrial entity to undertake. Such research can be performed in government/industry collaborative efforts with fewer problems related to intellectual property rights. The consensus of the workshop participants was that CBD could be such a program, and that, if successful, it would have major impacts on catalyst R\&D. Representatives of Allied-Signal, Amoco, Shell Development, and W.R. Grace expressed the majority's endorsement of the CBD approach to catalyst R\&D. They also clearly indicated that even the major corporations that they represent could not undertake such a long-term effort on their own.

The industrial participants also pointed out that support for catalyst research for commodity chemicals processes has dropped off in recent years for several reasons. Most notable is a general sense that major catalytic systems are operating well now and that further investment in research to improve their performance or to search for new catalysts is not warranted. Commodity chemicals are regarded as "cash cows." Such a philosophy is very 
short-sighted, especially in light of the stiff competition expected as the European Economic Community comes into being in 1992 .

Several participants felt that an unanticipated benefit of the CBD Program could be in training a group of excellent researchers in the field of catalysis and having these researchers available as U.S. industry ultimately begins reinvesting in catalysis research, perhaps within the next 5 years. The importance of catalysis to the U.S. economy is underscored by the fact that approximately $20 \%$ of our GNP is composed of products made through catalytic processes. The U.S. chemicals, petroleum refining, and petrochemicals industries are healthy at present. Some of the participants felt, however, that rather than waiting for problems to develop, now is the right time to initiate mutually beneficial collaborative efforts between government and industry. This approach may allow us to avoid the need for crash efforts to manage a crisis in international competition, such as Sematech in the semiconductor industry.

There has been increasing recognition of the need for collaborative efforts. Representatives from Shell Development Company indicated that not only are they increasing their internal commitment to catalyst research, but there is a planned program to seek out collaborative arrangements with government and industry to acquire new technologies. Their interest in the CBD Program is, therefore, quite high.

Al though the overall opinion of the workshop participants was favorable with respect to the CBD Program, there was also a healthy degree of skepticism, both in regard to the viability of the approach as well as the success of a collaborative effort in such a proprietary area. This skepticism is to be expected. CBD is a new and a very ambitious program. In addition, it is in an area where collaborative efforts have been rare. As the program progresses, the skepticism may be replaced by a sense of optimism and a desire to obtain the maximum benefits from the program. Such was ECUT's experience with their very successful Combustion Program. 


\subsection{CONTRACTUAL MECHANISMS}

Apart from a few major projects in the 1970 s related to synfuels, the chemicals, petroleum refining, and petrochemicals industries have not undertaken many R\&D projects jointly with DOE. In addition, since these industries are used to keeping much of their technical information proprietary, there is considerable interest in exploring the mechanisms which would allow industry/ government collaboration in CBD and still protect industry's rights. Mr. Bob Poteat (Patent Counse] from DoE's Oak Ridge Operations Office) was of great assistance at the workshop in explaining the various options, including the following:

- contracting/subcontracting - The national laboratories, under management and operating (M\&O) prime contracts, routinely enter into cost-shared R\&D subcontracts with industry. The rights to intellectual property and mechanisms to deal with subcontractors' proprietary data are spelled out in the subcontracts. DOE has broad authority to waive the government's rights in inventions arising under its R\&D contracts, including subcontracts entered into by the national laboratories under their M\&O contracts. A typical situation that justifies a waiver of rights in inventions is whether the contracting party agrees to substantially costshare in the research program.

- collaborative arrangements - This is a relatively new vehicle available to DOE's national laboratories for conducting costshared research for DOE. The national laboratories, as noted above, have for a number of years entered into cost-shared subcontracts with industry. On the other hand, there have been very few cost-shared agreements entered into by the national laboratories under their M\&O prime contracts. Collaborative arrangements involving "no funds" exchange have been entered into previously between the national laboratories and private industry.

More recently, a new initiative was undertaken by DOE with three pilot centers, the Argonne National Laboratory, the Los Alamos National Laboratory, and the Oak Ridge National Laboratory, in the area of high-temperature superconductivity (HTSC). The goal of this program is to foster cooperation in HTSC technology between the three pilot centers, private industry, and academia under costshared arrangements. This program allows the three designated national laboratories to undertake collaborative research where the full spectrum of exchange of funds (i.e., in, out, or no funds exchange) between the national laboratories and the collaborating partners can occur. The HTSC Pilot Center Program is currently being examined to determine whether the approach could be extended to other $D O E$ research activities. 
- research grants and assistance - This vehicle, which is covered under DOE's Federal Assistance Regulations, is 1 imited to those situations in which DOE is the contracting party, not one of its national laboratories. Hence, it is not believed to be a viable mechanism for ECUT's CBD research activities.

- cooperative research and development agreements - Recent legislation has established a new type of agreement that M\&O contractors may use after DOE issues regulations. The Cooperative Research and Development Agreements (CRADAs) established by this legislation appear to afford a useful contractual vehicle for the CBD research activities. The CRADAs require joint research Statements of Work (SOWs) that must be approved by DOE. The legislation authorizes the $M \& 0$ contractors to retain and use funds from the participants in the work to be performed under the CRADA and authorizes the M\&O contractors to use facilities and personnel to perform their part of the joint research work. It does not, however, include the authority to provide funds to the industrial participants.

Regardless of the collaborative mechanism employed, DOE's track record in maintaining proprietary data has been good. One example cited at the workshop was the methanol-to-gasoline project undertaken by Mobil with DOE support. Several other examples also exist. There was concern that if any of these projects leads to successful commercial products, the pressure on DOE to release proprietary data via the Freedom of Information Act (FOIA) will be much greater. That may be so. Despite its best intentions, whether DOE can resist such pressure cannot be judged until it is actually tested in court.

However, it was pointed out that proprietary data developed by industry with its own funds in a collaborative program belong to that industry. If DOE and national laboratory personnel gain access only to the information needed to effectively work on their part of the collaborative effort and do not take physical possession of any documents containing proprietary information, there is case law that holds that such documents are not "agency records" and could be withheld from disclosure under an FOIA request. In any event, proprietary data can be legally withheld under the (b)(4) exemption to any FOIA request.

The issue of intellectual property rights under cost-shared arrangements is more complex. Under Public Law 96,517, as amended, title to inventions made with DOE funds in small businesses and academic institutions is automatically, upon election by those entities, transferred to them. In DOE's M\&O 
contracts that are managed by universities, the patent rights to inventions are transferred to the managing university in accordance with the law. These facilities tend to pursue an aggressive policy of licensing those rights to industry, with strong encouragement from DOE. Other DOE laboratories managed by "for profit" organizations need to petition DOE to transfer patent rights on a case-by-case basis. Advance patent waivers may be requested under cost-shared industrial subcontracted research. However, the general experience is that if the cost sharing is $20 \%$ or more, the industrial concern is entitled to the patent rights.

In November 1989, Congress passed The National Competitive Technology Transfer Act, sponsored by Senator Domenici, which streamlines the DOE patent policy. The measure, signed into law on November 29, 1989 as Public Law 101-189, should resolve many of the outstanding issues relating to intellectual property rights as they pertain to DOE-funded projects.

Could these complex contractual and patent rights issues be showstoppers for industrial participation in the CBD Program? Most workshop participants did not think so. The general consensus was that a program as desirable as CBD needs to be pursued, and the details of how the collaboration wi11 occur need to be worked out on a case-by-case basis. A spectrum of contractual approaches is available, and industries willing to participate in the program will find the vehicle that is most suitable for their needs. A more important concern to the participants was that proper steps be taken to ensure that the commitment of the participating industries be high and that they play an active role in guiding and directing the effort of this longterm program.

\subsection{PREFERENTIAL TREATMENT OF U.S. INDUSTRY}

The CBD Program, if successful, could have a significant impact on the competitive position of U.S. industry. A key issue, therefore, is whether the fruits of this effort should be available to U.S. industry on a preferential basis. There was a general sentiment that mechanisms to assist U.S. industry in this important area were desirable. However, when it came to discussing 
specifics, the participants' reactions were decidedly mixed. The following are several relevant issues that emerged:

1. A strict interpretation of a "U.S. company" could exclude major chemicals and petrochemicals companies that do most of their business in the U.S. (e.g., Celanese, She11, BP America, ICI America). The workshop participants had mixed reactions to excluding such well-known entities in the U.S. marketplace.

2. Another opinion expressed by several participants was that the results of a government-supported research progran could not be kept confidential. Consequently, attempts to restrict it to U.S. companies would not succeed and may even be counterproductive.

3. A third viewpoint was that the global marketplace, with multinationals operating across national boundaries, makes it extremely difficult to restrict information within national boundaries. However, it was pointed out that the Japanese seem to do a pretty good job of keeping U.S. companies from acquiring their technology.

The sense of the workshop was to request DOE to explore avenues to provide preferential treatment for U.S.-based corporations.

The workshop's primary message was that CBD is an attractive approach which, if successful, could have major impacts on the U.S. chenicals industry. Based on the workshop discussions, it is clear that industry is willing to participate in this long-term effort. Concerns associated with patent rights and the protection of trade secrets are not serious enough to be considered "showstoppers" to a collaborative effort between ECUT and industry. Mechanisms must be explored to give preferential treatment to U.S. industry to use the fruits of this research effort. There is also a sense of resignation that such efforts may not be successful.

\subsection{THE CBD PROGRAM PLAN}

ECUT considered the views expressed at the workshop in developing a plan to encourage government/industry collaboration in the CBD Program. The plan calls for competition among the DOE national laboratories for CBD funding. All proposals were required to discuss innovative CBD research concepts and clearly delineate how the DOE laboratory intended to work with industrial partners in conducting the research project. In the project selection phase, special emphasis was given to proposals that described a well-integrated 
program between the 1 aboratory and its industrial partners. The proposals were required to describe the extent of cost sharing, the possibility of exchange of technical personnel, and the role industry will play in establishing project priorities. ECUT anticipated that the selected proposals would form the kernel of key working groups in the CBD Program as it continues to grow.

The ECUT program manager appointed an advisory panel to assist in setting program objectives and evaluating progress. The Technical Advisory Panel was responsible for recommending research goals, evaluating suggested approaches, and monitoring technical progress. This panel selected five winners from the proposals received from the DOE laboratories in response to the CBD initiative. Panel members included nationally recognized experimental and theoretical researchers from industry and academia. 


\subsection{CONCLUSIONS}

In embarking on the CBD Program, ECUT realized that it might take up to a decade before large-scale atomic simulations of catalyst systems would be possible. Nonetheless, the CBD Program intends to develop experimentally validated computational tools for the chemicals, petroleum refining, and petrochemicals industries which are so structured that intermediate results are valuable to industry, and will be continuously incorporated by industry in their ongoing research efforts. The synergistic interaction between experiments, theory, and modeling is essential for the success of this approach and will be strongly emphasized. Thus, the CBD Program does not contemplate displacement of experiment by theory. Instead, it encourages developing a modeling and computer simulation-based approach for guiding laboratory experimentation and catalyst development. This will allow researchers to be more creative and efficient in the conceptualization stage and will allow optimization of the product to occur in the laboratory instead of during expensive pilot plant tests or commercial operation.

Interest in the $C B D$ approach was evidenced by the strong industry participation in ECUT's CBD workshops in FY 1989. Industrial and national laboratory workshop participants established a CBD research agenda and also discussed mechanisms for government/industry collaboration. The industrial support is encouraging, since implementing an effective CBD Program requires developing true partnerships between the national laboratories and industry. The goals and objectives of the program will be set in consultation with a panel of experts from industry and academia. Research topics addressed by the program must be of interest to industry and must also satisfy DOE's dual missions of improving energy security (by developing efficient energyconversion and conservation technologies) and maintaining U.S. competitiveness. ECUT's goal was to demonstrate the technical feasibitity of the CBD concept in five years, knowing that it would take at least a decade to fully realize its potential. 
The overall strategy of $\mathrm{CBD}$ is to closely couple the experimental, theoretical, and modeling aspects of catalyst R\&D to improve the efficiency of the whole process. A successful CBD Program must:

- decrease the time 1 ag between generating experimental catalysis data and refining the specific theory

- stimulate ideas for new catalyst systems through close collaboration between experimentalists and theoreticians

- expand the usefulness of the experimental data being accumulated by building databases and predictive models and continually revising them as new data are obtained

- increase the efficiency of catalyst screening by providing guidance to the researchers as soon as possible

- facilitate the transition from basic knowledge of molecular-level behavior to generic applied-catalys is research concepts.

This assessment establishes that the CBD Program is clearly in the national interest and does fit the missions of ECUT and DOE. The case studies, the interviews, and the workshops have repeatedly demonstrated the contributions that catalysis can make in improving our energy security. Catalytic processes potentially will allow us to continue to use our predominant fossil fuel resource (i.e., coal) in an environmentally acceptable manner, and al so will foster the increased use of alternative fuels from renewable energy sources such as biomass. Success in these areas will help address, in a costeffective manner, some of the major environmental issues facing this nation (e.g., climate change and poor urban air quality).

Catalysis plays a fundamental role in the chemicals and petrochemicals industries, and success in the CBD Program will help maintain or even increase the competitive position of these vital industries. Recent studies have shown that these industries have done well to adapt to the global marketplace, however, there is some concern whether the same pace of technological innovation will continue because of the recent gradual decline of R\&D support in these industries. The enabling technologies developed in the CBD program may serve as an incentive to reinvigorate catalyst R\&D in this country, a theme that clearly emerged in the interviews conducted as a part of this study. 
Biotechnology is an emerging industry, and competition between the U.S., Japan, and Europe is already fierce. The U.S. effort is directed mainly toward the pharmaceutical and agricultural sectors. Biocatalysis research undertaken as part of the CBD Program will direct much needed R\&D investment in developing bioprocesses for producing industrial and energy-related chemicals. If successful, it will make a major contribution to developing a totally new and potentially large market for biochemical technologies and provide U.S. industry a technological lead in this important area.

It is clear that the CBD Program is a very desirable program for ECUT and its successor (the Advanced Industrial Concepts Division of the Office of Industrial Technologies) to support. However, it is essential that it be strongly industry-guided, thus ensuring that it is focused to address industrial needs. True sharing of resources (human and monetary) and information between industry and the national laboratories will be critical to the program's success.

Since the CBD Program will be industry-guided, industrial inputs to the program have been aggressively sought from the very beginning. The program reflects a consensus view of the biocatalysis and chemical catalysis communities from both industry and the DOE laboratories. At every stage of the program, technology will be adequately developed to allow its exploitation by industry. Licensing and spin-off companies are technology transfer mechanisms for facilitating this integration of CBD products into the industrial catalyst R\&D process.

ECUT and industry embarked on the CBD Program with the first step being the national laboratory/industry initiative. This involved the laboratories teaming up with industrial partners and proposing CBD projects in various industrially relevant catalyst research areas. Reactions will be investigated with a battery of experimental techniques and theoretical treatments to understand and model the fundamental steps involved. The successful proposals will form the basis of working groups that will continue to operate throughout the entire duration of the program. More groups will be added as the program develops, depending on industry needs. 
The industry/DOE laboratory consortia thus selected are expected to continue their involvement throughout the duration of the program, provided that the projects continue to be consistent with the program $p l$ an and that their annual progress is judged to be excellent. This approach will not only allow continuity in the program, but also develop centers of excellence at the DOE laboratories where industrial researchers can use advanced methodologies to address important catalyst research issues. It will also allow the DOE laboratories to develop close relationships with industry such that these centers become self-sustaining, with industrial support, even after the CBD Program is concluded.

Continued industrial participation and effective technology transfer will depend on contractual arrangements established between the DOE laboratories and their industrial partners regarding intellectual property and the handling of proprietary data. Several mechanisms exist to accomplish these objectives. ECUT strongly encouraged the laboratories to fully use these mechanisms to ensure viable working relationships with industry. It was also ECUT's intention to provide U.S. industry a preferred position to use the products of the CBD Program. ECUT thus intended to limit the dissemination of enabling technologies, such as computer codes, consistent with existing DOE policies.

Industrial catalyst research is considered to be highly proprietary, and industry is quite reluctant to part with their data. In fact, the issue of intellectual property rights is of great concern. In the past, DOE has dealt with such concerns successfully in several major programs through prior negotiations between the DOE laboratories and industrial participants involved. It is anticipated that in the CBD Program, these concerns will be resolved in a similar manner. However, it is only with time, as industry and ECUT (or its successor) start working together and building up mutual trust and realizing the value of their efforts that the issues will be resolved completely.

Basic research in catalysis, surface science, theory, and computational science is supported by DOE'S Basic Energy Sciences (BES) and the National Science Foundation (NSF). CBD clearly needs to build on the foundation laid by these basic research efforts, as well as provide feedback to encourage basic research in specific areas. It also needs to disseminate the results to 
other industry groups involved in catalysis research, such as the Gas Research Institute (GRI) and the Electric Power Research Institute (EPRI). The management of the CBD Program will focus on maintaining close contacts with the relevant program managers and principal investigators of these related programs. In addition, an annual meeting of a11 CBD researchers will be arranged to discuss progress and promote interaction between the various ongoing investigations. 


\subsection{REFERENCES}

A. G. Bayer Company. November 1979. "Acetic Acid." Hydrocarbon Processing $58(11): 120$.

American Chemical Society (ACS). 1984. Key Chemicals and Polymers. 6th ed. American Chemica] Society, Washington, D.C.

Borman, S. 1989. "Improved Access to Supercomputers Boosts Chemical Application." Chemical and Engineering News 67(29):29-37.

Boston, J. F. February 1990. "Process Modeling Works." Chemtech, p. 100.

Broach, R. W., et al. February 1989. Assessment of Theoretical and Experimental Tools for Applied Research and Exploratory Development in Certain

. Energy Technologies. ORNL/Sub/86-00210/1, Allied-Signal Engineered Materials Research Center, Des Plaines, Illinois.

Chemical and Engineering News. 1984. "C8EN's Top 50 Chemical Products and Producers, " 62(19):7-9.

Chemical Engineering. 1983. Sources and Production Economics of Chemical Products. McGraw-Hill Publishing Company, New York.

Chemical Week. June 28, 1989. "Special Report-Catalysts '89."

Chen, N. Y. and T. F. Degnan. 1988. "Industrial Catalytic Applications of Zeolites." Chemical Engineering Progress 84(2):32-41.

Chianelli, R. R. 1985. "Fundamental Studies of Transition Metal Sulfide Hydrodesulfurization Catalysts." Catalysts and Surface Science, eds.

H. Heinemann and G. A. Somarjai. Marce] Dekker, New York.

Data Resources, Inc. 1978. Energy Conservation in the Petrochemicals Industry: An Analysis Using Industry Process and Mathematical Models. Data Resources, Inc., Lexington, Massachusetts.

Eberhardt, J. J., and L. Keay. 1989. "A Historical Perspective of the ECUT Catalysis/ Biocatalysis Program 1980-1989." D0E/ECU-89/1, U.S. Department of Energy, Oak Ridge, Tennessee.

Energy and Environmental Analysis, Inc. (EEAI). 1983. Industrial Energy Productivity Project--Final Report: The Chemicals Industry. Volume 5, DOE/CS/40151-I, U.S. Department of Energy, Washington, D.C.

Fassbender, L. L., R. K. Sen, and J. K. Young. 1990. Proceedings of the Catalysis-by-Design Workshops. PNL-SA-18355, Pacific Northwest Laboratory, Richland, Washington. 
Gaines, L. L., and S. Y. Shen. 1980. Energy and Materials Flows in the Production of 0lefins and Their Derivatives. ANL/CNSV-9, Argonne National Laboratory, Argonne, Illinois.

Gardner, R. A. February 1988. "Catalysis Prediction Saves Research Time." Research and Development, p. 108.

Greek, B. F. 1984. "Elastomers Finally Recover Growth." Chemical and Engineering News 62(18):35-36.

Hame1, B. B., N. L. Brown, and B. A. Nedman. 1979. Energy Analys is of 108 Processes. C00-2862-T1, Drexel University, Philadelphia, Pennsylvania.

Hardy, R. W. F. and D. J. G1ass. Spring 1985. "Our Investment: What is at Stake?" Issues in Science and Technology, p. 69.

Hegedus, L. L. October 1980. "Catalysts, Computers, and Cars: A Growing Symbiosis." Chemtech, p. 630 .

Hegedus, L. L., editor. 1987. Catalyst Design: Progress and Perspectives. John Wiley, New York.

Hettinger, W. P., L. E. Busch, and R. P. Krock. 1984. "Heavy 0 il Processing Alternatives: The Ashland Approach." Presented at the 0 il and Gas Conference, Dallas, Texas, June 4-7, 1984.

Keyworth, G. A. February 1985. "Science and Technology Policy: The Next Four Years". Technology Review 88(2):44-53.

McKetta, J. 1977. Encyclopedia of Chemical Processing and Design. Volume 2, Marcel-Dekker Publishing Company, New York.

Meise1, S. L. January 1988. "Catalysis Research Bears Fruit." Chemtech, p. 32 .

National Academy of Sciences (NAS), National Materials Advisory Board. 1986. Bioprocessing for the Energy-Efficient Production of Chemicals. Report NMAB-428. Nationa1 Academy Press, Washington, D.C.

Office of Technology Assessment (OTA). April 1981. Impacts of Applied Genetics. Congress of the United States, Washington, D.C.

Office of Technology Assessment (OTA). January 1984. Commercial Biotechnology. Congress of the United States, Washington, D.C.

Pimente1, G. C. 1985. Opportunities in Chemistry. National Academy Press, Washington, D.C.

Shreve, N., and S. J. Brink. 1977. Chemical Process Industries. 4th ed. McGraw-Hill Publishing Company, New York. 
Sinfelt, J. H. 1987. "Catalyst Design: Selected Topics and Example". Recent Developments in Chemical Process and Plant Design. eds. Y. A. Liu,

H. A. McGee, and W. R. Epperly. John Wiley Publishing, New York.

Siwolop, S. September 1989. "Agents of Change". Financial Horld, pp. 44-46.

Tornatzky, L. G., T. S. Solomon, and J. D. Eveland. February 1987. Examining Collaborative Arrangements in Advanced Materials and Other High-Technology Fields. United States Congress, Office of Technology Assessment. Washington, D.C.

Trimm, D. L. 1980. Design of Industrial Catalysts. Elsevier Science Publishing Company, Inc., New York. 


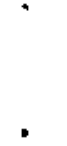




\section{DISTRIBUTION}

No. of

Copies

\section{OFFSITE}

12 DOE Office of Scientific and Technical Information

M. Alper

Deputy Director

Center for Advanced Materials

Lawrence Berkeley Laboratory

University of California

Berkeley, CA 94720

R. T. Angelici

Iowa State University

Spelling Hall

Ames, IA 50011

D. Anton

Experimental Station

E. I. DuPont de Nemours \& Co.

Building 328

P.0. Box 80328

Wilmington, DE 19880-0328

J. Baez

Monsanto Company

700 Chesterfield Village

Parkway

St. Louis, MO 63198

A. Bakac

Iowa State University

Spelling $\mathrm{HaTl}$

Ames, IA 50011

A. Bell

Dept. of Chemical Engineering

University of California

Gilman Hail, Roon 201C

Berkeley, CA 94720
No of

Copies

D. Beratan

Jet PropuTsion Laboratory

California Insititute of

Technology

4800 Oak Grove Dr.

Pasadena, CA 91109

K. Bernard

Cray Research

1331 Pennsylvania Ave., NW

Suite $1331 \mathrm{~N}$.

Washington DC 20004

P. Betten

Argonne National Laboratory

9700 So. Cass Ave.

Argonne, IL 60439-4831

W. Bialek

Dept. of Physics

University of California

Berkeley, CA 94720

H. Blanch

Dept. of Chemical Engineering

University of California

$110 \mathrm{Gi} T m a n \mathrm{Hall}$

Berkeley, CA 94720

R. Blint

General Motors Research

Laboratory

30500 Mound Rd.

Warren, MI 48090-9055

M. Boudart

Catalytica, Inc.

430 Ferguson Dr., Building 3

Mountain View, CA 94043

R. Broach

UOP Research Center

50 East Algonquin Rd.

Des Plaines, IL 60017-5016 
No. of

Copies

P. Brodsky

Monsanto Company

800 N. Lindburgh

St. Louis, MO 63167

G. Brown

Dean of Colleges

Case Western Reserve University

Crawford $\mathrm{Hall}$, 7th Floor

Cleveland, $\mathrm{OH} 44106$

G. Carlson

Fuel Science Division 6211

Sandia National Laboratories

P.0. Box 5800

Albuquerque, NM 87185-5800

H. Chum

Chemical Conversion Branch

Solar Energy Research

Institute

1617 Cole Blyd.

Golden, CO 80401

J. Coleman

Monsanto Chemical Company

800 N. Lindburgh Blvd.

St. Louis, MO 63167

R. Cotterman

FCC Catalyst Research

Washington Research Center

W.R. Grace \& Company

7379 Route 332

Columbia, MD 21044

S. Cramer

NSLS

Brookhaven National Laboratory

Building 725D

Upton, NY 11973

D. Crea

FMC Corp.

P.0. Box 4111

Pocatello, ID 83202
No. of

Copies

J. B. Cropley

Union Carbide

3200 Kaenawha Turnpike

South Charleston, WV 25303

D. Darensbourg

Dept. of Chemistry

Texas A\&M University

College Station, TX 77843

W. Degrado

Central R \& D Dept.

E.1. DuPont de Nemours \& Co.

Experimental Station

Wilmington, DE 19898

R. Detroy

Allied Signal

50 East Algonquin Rd.

Des Plaines, IL 60017

G. Dilworth

U.S. Dept. of Energy

ER-17

19901 Germantown Rd.

Gemantown, MD 20545

D. Dixon

Central $R$ \& $D$

E.I. DuPont de Nemours \& Co.

Experimental Station E 328

Wilmington, DE 19898

W. Dowd

Central Research-0rganic Chemicals \& Polymers

The Dow Chemical Company

1776 Building

Midland, MI 48674

M. Droege

Lawrence Livermore National Lab.

$L=325$

P.0. Box 808

Livermore, CA 94550 
No. of

Copies

D. Dubois
Solar Energy Research
Institute
1617 Cole Blyd.
Golden, CO 80401

D. F. Durso

Executive Director

Council for Chemical Research, Inc.

One Bethleham Plaza, Suite 911

Bethlehem, PA 18018

\section{R. Eades}

Cray Research

1333 Northland Dr.

Mendota Heights, MN 55120

J. J. Eberhardt

U.S. Dept. of Energy

Forrestal Building

1000 Independence Ave. S.W.

Washington, DC 20585

J. Ebner

Monsanto Company

Mail Zone Q4E

800 North Lindbergh Blyd.

St. Louis, MO 63167

J. H. Espenson

Program Director

Iowa State University

Spelling Hall

Ames, IA 50011

\section{G. Fitzgerald}

BioSym Technologies, Inc. 10065 Barnes Canyon Rd.

San Diego, CA 92121

D. Forster

Monsanto Company

800 N. Lindburgh Blvd.

St. Louis, MO 63167
No. of

Copies

A. J. Freeman

Physics Dept.

Northwestern University

Evanston, IL 60208

E. Garcia

Lawrence Livermore National Lab.

P.0. Box 808

Livermore, CA 94550

H. Garfinkel

Vice President

Research \& Development

Englehard Corporation

CN40 Memio Park

Edison, NJ 08818

B. Gartin

Catalytica, Inc.

Building 3

430 Ferguson Dr.

Mountain View, CA 94043

B. C. Gerstein

Iowa State University

Spelling Hall,

Ames, IA 50011

G. Glover

Monsanto Company

AA4I

700 Chesterfield Village

Parkway

St. Louis, MO 63198

W. A. Goddard, III

California Institute of

Technology

127-72

Pasadena, CA 91125

A. Goland

Dept. of Applied Science

Brookhaven National Laboratory

Building 815

Upton, NY 11973 
No. of

Copies

R. Grasselli

Catalyst Research and Development

Paulsboro Research Laboratory

Mobil R \& D Center

Paulsboro, NJ 08066

J. Grate

Catalytica, Inc.

Building 3

430 Ferguson Dr.

Mountain View, CA 94043

T. J. Gross

U.S. Department of Energy

Forrestal Building/CE-20

1000 Independence Ave., S.W.

Washington, DC 20585

M. E. Gunn

U.S. Department of Energy

Forrestal Building/CE-232

1000 1ndependence Ave., S.W.

Washington, DC 20585

W. Haag

Mobil R\&D Corporation

P.0. Box 1025

Princeton, NJ 08540

J. Hay

Los Alamos National Laboratory

T-12, MS J569

P.0. Box 1663

Los Alamos, NM 87545

B. Haymore

Corporate Research Laboratory

Monsanto Company

Q3E

800 N. Lindburgh Blvd.

St Louis, MO 63167
No. of

Copies

L. Hegedus

Washington Research Center

W. R. Grace \& Co.

7379 Route 332

Columbia, MD 21044

F. Heineken

Biotechnology Program Director

Directorate for Engineering

National Science Foundation

1800 G. St. N.W.

Washington, DC 2055D

H. Heinemann

Center for Advanced Materiais

Lawrence Berkeley Laboratory

One Cyclotron Rd.

Berkeley, CA 94720

A. Hensiey

Research and Development Dept.

Amoco $0 \mathrm{il}$ Company

P.0. Box 3011

Naperville, IL 60566

G. Hill

Senior Vice President

Lubrizol Corporation

29400 Lakeland Blvd.

Wickliffe, OH 44092

S. Ho

Eastman Kodak

343 State St.

Rochester, NY 14608

A. Hope

BioSym Technologies, Inc.

1515 Route 10, Suite 1000

Parsippany, NJ 07054

J. Horsley

Catalytica, Inc.

430 Ferguson, Inc.

Mountain View, CA 94043 
No. of

Copies

L. Iton

Material Science Division Argonne National Laboratory

Building 200

9700 So. Cass Ave.

Argonne, IL 60439

L. Johnson

Idaho National Engineering Lab.

EG\&G Idaho, Inc.

P.0. Box 1625

Idaho Fatls, ID 83415

L. Keay

U.S. Dept. of Energy

Idaho Operations Office

785 DoE Place

Idaho Falls, ID 83415

P. Kilty

Manager

Chemical Catalysis Research

Shel1 Development Company

Westhollow Research Center

3333 Highway Six South

Houston, TX 77082

T. S. King

Chemical Engineering

Iowa State University

Sweeney $\mathrm{Hall}$

Ames, IA 50011

A. Klibinov

Dept. of Chemistry

Massachussetts Institute of Technology

Cambridge, MA 02139

D. Klipstein

BioSym Technologies, Inc.

10065 Barnes Canyon Rd.

San Diego, CA 92121
No. of

Copies

A. Kozinski

Vice President

Research

Amoco 0 il Company

P.0. Box 3011

Naperville, IL 60566

E. Kugler

U.S. Dept. of Energy

ER-142

19901 Germantown Rd.

Germantown, MD 20545

J. Laity

Director

New Chemical Technology R\&D

Westhollow Research Center

Shell Oevelopment Co.

P.0. Box 1380

Houston, TX 7251-1380

R. Lambert

U.S. Dept. of Energy

Forrestal Building/CE-42

1000 Independence Ave. S.W. Washington, DC 20585

A. Landgrebe

U.S. Dept. of Energy

Forrestal Building/CE-32

1000 Independence Ave. S.W.

Washington, DC 20585

J. W. Linowski

Central Research-Catalysis Laboratory

The Dow Chemical Company

1776 Building

MidTand, MI 48674

J. Low

UOP Research Center

50 East Algonquin Rd.

Des Plaines, IL 
No, of

Copies

R. Mariane 11 i

U.S. Dept. of Energy

ER-14

19901 Germantown Rd.

Germantown, MD 20545

C. Marshall

Research and Development Department

Amoco 0il Company

P.0. Box 3011

Naperville, IL 60566

J. McCollum

Amoco $011 \mathrm{Co}$.

$\mathrm{M} / \mathrm{S} \mathrm{H} 2$

P.0. Box 400

Naperville, IL 60566

K. McHenry

Amoco 0 il Company

P.0. Box 3011

Napervitle, IL 60566

M. Mc Intosh

Energy Systems Oivision

Argonne National Laboratory

Building 362

9700 So. Cass Ave.

Argonne, IL 60439-4831

H. McVeigh

Paulsboro Research Labs

Mobil 0 il Co.

Billingsport Rd.

Paulsboro, NJ 08066

E. Moorehead

Manager

Petroleum Catalyst Evaluation

Engelhard Corp.

CN40 Men lo Park

Edison, NJ 08818
No. of

Copies

J. Newsome

Corporate Research Center

Exxon Research and Engineering Corp.

Route 22E

Annandale, NJ 08801

J. Norbeck

Scientific Research Laboratory

Ford Research \& Engineering Center

Rm. E3172

21500 Oakwood Blvd.

Dearborn, MI 48121

B. 0lafson

BioDesign, Inc.

199 So. Los Robles Ave

Suite $\# 540$

Pasadena, CA 91101

S. Overbury

Chemistry Oivision

Oak Ridge National Laboratory

P.0. Box 2008

Oak Ridge, TN 37831-6201

P. Owen

Innovation Development Dept.

2030 Willard H. Dow Center

Midland, MI 48674

G. Parks

Phillips Petroleum

$356 \mathrm{PL}$

Bartlesville, OK 74004

G. Parshall

Director of Research

E.I. duPont de Nemours \& Co.

P.0. Box 80328

Experimental Station

Wilmington, OE 19880-0328

B. Penquite

Celgene Corp.

7 Powder Horn Dr.

Warren, NJ 07060

Distr. 6 
No. of

Copies

C. Pereira

Washington Research Center

W.R. Grace \& Co.

7379 Route 332

Columbia, MD 21044

G. Petersen

Jet Propulsion Laboratory

California Institute of

Technology

$\mathrm{M} / \mathrm{S}$ 125-112

4800 Oak Grove Dr.

Pasadena, CA 91109

L. Powers

Director

Center for Biocat. Science \&

Tech.

Utah State University

Logan, UT 84332-4630

A. Redondo

Los ATamos National Laboratory

MEE-11, MS D429

P.0. Box 1663

Los Alamos, NM 87545

P. Reilly

Chemical Engineering

Iowa State University

Sweeney HalT

Ames, IA 50011

R. Rogers

Idaho National Engineering Laboratory

EG\&G Idaho, Inc.

P.0. Box 1625

Idaho Falls, ID 83415

J. Rosenthat

Process Research Division

Chevron Research Company

576 Standard Ave.

Richmond, CA 94802
No. of

Copies

\author{
A. J. Russell \\ Dept. of Chen. \& Petroleum \\ Eng. \\ University of Pittsburgh \\ Pittsburgh, PA 15260 \\ W. Sachtler \\ Catalysis Center \\ Northwestern University \\ 2137 Sheridan Rd. \\ Evanston, IL 60208 \\ P. Salmon-Cox \\ U.S. Department of Energy \\ Forresta] Building/CE-142 \\ 1000 Independence Ave., S.W. \\ Washington, DC 20585 \\ R. Sapienza \\ Dept. of Applied Sciences \\ Brookhaven National Laboratory \\ Building 120 \\ Upton, NY 11973 \\ G. L. Schrader \\ Chemical Engineering \\ Iowa State University \\ Sweeney Hall \\ Ames, IA 50011 \\ A. W. Schwabacher \\ Chemistry Dept. \\ Iowa State University \\ Gilman Hall \\ Ames, IA 50011 \\ C. Scott \\ Chemical Technology Division \\ Oak Ridge National Laboratory \\ P.0. Box 2008 \\ Oak Ridge, TN 37831-6226 \\ R. Sen \\ R. K. Sen \& Associates \\ 3808 Veazey St. N.W. \\ Washington, DC 20016
}


No. of Copies

J. Shelnutt

Fuel Sciences Division 6211

Sandia National Laboratories

P.0. Box 5800

Albuquerque, NM 87185-5800

G. Shier

The Dow Chemical Company

1801 Building

Midland, MI 48674

E. Shustovich

Corporate Research Laboratory

Eastman Kodak

343 State St.

Rochester, NY 14650

J. Sinfelt

Corporate Research Laboratory

Exxon Research and Engineering Company

clinton Township, Route 22 East

Annandale, NJ 08801

J. Smith

Union Carbide Techinical

Center

P.0. Box 8361

Building 2000, Room 2111

South Charleston, WV 25303

G. Somorjai

Center for Advanced Materials

Lawrence Berkeley Laboratory

1 Cyclotron Rd.

Berkeley, CA 94720

W. Sonnet

Office of Industrial Programs

U.S. Dept. of Energy

Forrestal Building/CE-142

1000 Independence Ave. S.W.

Washington, DC 20585
No. of

Copies

A. J. Streb

U.S. Department of Energy

Forrestal Building/CE-10

1000 Independence Ave., S.W.

Washington, DC 20585

K. Taylor

General Motors Research Laboratory

30500 Mound Rd.

Warren, MI 48090-9055

W. S. Trahanovsky

Chemistry Dept.

Iowa State University

Gilman Hall

Ames, IA 50011

G. Voecks

Jet Propulsion Laboratory

$\mathrm{M} / \mathrm{S} 84$

4800 0ak Grove Dr.

Pasadena, CA 91109

D. Washecheck

Amoco 0 il Company

P.0. Box 3011

Naperville, IL 60566

M. Wasielewski

Chemistry Division

Argonne National Laboratory

Building 200

9700 So. Cass Ave.

Argonne, IL 60439-4831

V. Weekman

Central Research Labs

Mobil Oil Co.

P.0. Box 1025

Princeton, NJ 08540

D. Wiley

Office of Industrial Programs

U.S. Dept. of Energy

Forrestal Building

1000 Independence Ave. S.W.

Washington, DC 20585 
No. of Copies

A. Wilks

Research \& Technology

Allied Signal

50 East Algonquin Rd.

Des Plaines, IL 60017

R. Winans

Chemistry Division

Argonne National Laboratory

Building 200

9700 So. Cass Ave.

Argonne, IL 60439-4831

J. Wise

Research

Mobil 0il Co.

P.0. Box 1031

Princeton, NJ 08540

J. Wolfram

Idaho National Engineering Lab.

EG\&G Idaho, Inc.

P.0. Box 1625

Idaho Falls, ID 83415

J. Woodward

Chemical Technology Division

Oak Ridge Nationa] Laboratory

P.0. Box 2008

Oak Ridge, TN 37831-6194

C. Wyman

Biotechnology Research Branch

Solar Energy Research

Institute

1617 Cole Blyd.

Golden, CO 80401-3393

0 . Zaborsky

0zcom International

P.0. Box 7604

McLean, VA 22106
No. of

Copies

ONSITE

DOE Richland Operations Office

R. B. Goranson

35 Pacific Northwest Laboratory

R. C. Adams

E. G. Baker

R. S. Butner

D. E. Deonigi

L. L. Fassbender (20)

L. J. Sealock

L. J. Silva

M. R. Thompson

T. A. Williams

J. K. Young

Publishing Coordination

Technical Report Files 
